\title{
Development of high resolution land surface parameters for the Community Land Model
}

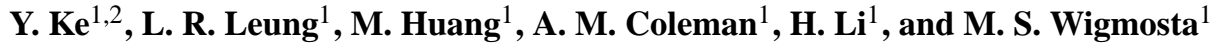 \\ ${ }^{1}$ Pacific Northwest National Laboratory, 902 Battelle Boulevard, Richland WA, 99352, USA \\ ${ }^{2}$ Department of Resource Environment and Tourism, Capital Normal University, 105 Xi San Huan Bei Lu, \\ Beijing, 100048, China
}

Correspondence to: L. R. Leung (ruby.leung@pnnl.gov)

Received: 3 April 2012 - Published in Geosci. Model Dev. Discuss.: 12 June 2012

Revised: 19 September 2012 - Accepted: 21 September 2012 - Published: 6 November 2012

\begin{abstract}
There is a growing need for high-resolution land surface parameters as land surface models are being applied at increasingly higher spatial resolution offline as well as in regional and global models. The default land surface parameters for the most recent version of the Community Land Model (i.e. CLM 4.0) are at $0.5^{\circ}$ or coarser resolutions, released with the Community Earth System Model (CESM). Plant Functional Types (PFTs), vegetation properties such as Leaf Area Index (LAI), Stem Area Index (SAI), and nonvegetated land covers were developed using remotely sensed datasets retrieved in late 1990's and the beginning of this century. In this study, we developed new land surface parameters for CLM 4.0, specifically PFTs, LAI, SAI and non-vegetated land cover composition, at $0.05^{\circ}$ resolution globally based on the most recent MODIS land cover and improved MODIS LAI products. Compared to the current CLM 4.0 parameters, the new parameters produced a decreased coverage by bare soil and trees, but an increased coverage by shrub, grass, and cropland. The new parameters result in a decrease in global seasonal LAI, with the biggest decrease in boreal forests; however, the new parameters also show a large increase in LAI in tropical forest. Differences between the new and the current parameters are mainly caused by changes in the sources of remotely sensed data and the representation of land cover in the source data. Advantages and disadvantages of each dataset were discussed in order to provide guidance on the use of the data. The new high-resolution land surface parameters have been used in a coupled landatmosphere model (WRF-CLM) applied to the western US to demonstrate their use in high-resolution modeling. A remapping method from the latitude/longitude grid of the CLM
\end{abstract}

data to the WRF grids with map projection was also demonstrated. Future work will include global offline CLM simulations to examine the impacts of source data resolution and subsequent land parameter changes on simulated land surface processes.

\section{Introduction}

As the terrestrial component of earth system models, land models simulate land surface processes that control the exchanges of water, energy and momentum between soil, vegetation and atmosphere. The Community Land Model (CLM) is a land model within the Community Earth System Model (CESM), formerly known as Community Climate System Model (CCSM) (Oleson et al., 2010). It was designed for coupling with atmospheric models such as Community Atmosphere Model (CAM), and provides estimation of surface albedos, upward longwave radiation, sensible heat flux, latent heat flux, water vapor flux and surface $\mathrm{CO}_{2}$ exchanges required by atmospheric models (Oleson et al., 2010). The land surface parameters in CLM are represented with a nested subgrid hierarchy in which spatial heterogeneity of the land surface is considered for each model grid. Grid cells are composed of a different number of land units including glacier, lake, wetland, urban and vegetated surfaces. Vegetated surfaces are represented with composition of 15 possible Plant Functional Types (PFTs) plus bare ground. For vegetation characteristics, leaf and stem area indices and canopy top and bottom height parameters are described for each PFT. Soil color, soil texture and soil organic matter density, in 
addition to a number of urban parameters, are required for ground surface parameters.

CLM has been widely applied at continental and global scales to understand how land processes and anthropogenic impact on land states affect climate and spatiotemporal change of the climate (e.g. Bonan et al., 2002b; Dickinson et al., 2006). In continental or global studies, CLM typically operates over a coarse spatial resolution (e.g. $1^{\circ}$ by $1^{\circ}$ or bigger grid cells). Recent studies have emerged to apply CLM at the regional scale and even at the small watershed scale (Li et al., 2011). CLM has also been used in an initial effort as the land surface component of a regional earth system model based on the Weather Research and Forecasting (WRF) model (Leung et al., 2006). Regional and subregional applications require CLM to run at much finer spatial resolution (e.g. $1-20 \mathrm{~km}$ grid cells) in order to better represent the effects of land surface heterogeneity and provide climate information at the scales needed for impact assessment (Leung et al., 2006). These requirements demand land surface parameters to be provided at a resolution similar to or finer than that of the model. In the current version of CLM (CLM 4.0), the officially released land surface parameters are provided at $0.5^{\circ}$ by $0.5^{\circ}$ or coarser resolutions. For example, lake and wetland data were derived from Cogley's (1991) $1^{\circ}$ by $1^{\circ}$ data for perennial freshwater lakes and swamps/marshes; PFT Leaf Area Index (LAI) were derived from Moderate Resolution Imaging Spectroradiometer (MODIS) satellite data and were aggregated to a $0.5^{\circ}$ resolution. Although the PFT and PFT LAI parameters were originally developed at spatial resolution of $0.05^{\circ}$ and then aggregated to $0.5^{\circ}$ (Lawrence and Chase, 2006, 2007), the finer resolution datasets have not been officially released with CESM so the default CLM 4.0 land surface parameters are still provided at $0.5^{\circ}$ resolution. Only registered developers of CESM have access to the higher resolution PFT, but the corresponding $0.05^{\circ}$ PFT LAI dataset is not available even by request due to noise in the LAI data at the fine resolution (D. M. Lawrence, personal communication, 2012). There are limitations in using these coarse-resolution surface datasets to support regional-scale modeling.

In addition to the coarse spatial resolution, the CLM 4.0 land surface parameters were generated using temporally mixed, somewhat outdated, and in some cases, not fully validated data sources. For example, the lake and wetland data was sourced from Global Hydrographic Data in 1991 (Cogley, 1991); PFTs fractional cover data was derived using a combination of the 2001 MODIS Vegetation Continuous Field (VCF), MODIS land cover product with unknown year (Lawrence and Chase, 2006, 2007), and 19921993 AVHRR Continuous Field Tree Cover Project data (Lawrence and Chase, 2007; Lawrence et al., 2011); the MODIS VCF dataset, which contains proportional estimates of bare soil, trees and herbaceous vegetation in each pixel area, has not been extensively validated, especially for the estimates of bare soil and herbaceous cover (Hansen et al., 2003; Jeganathan et al., 2009; Montesano et al., 2009).

In recent years, substantial effort has been made in developing improved characterizations of global land cover and vegetation based on MODIS imagery, or other available satellite sensor products, in order to provide accurate and continuous land parameters for land surface and climate modeling. The MODIS Collection 5 Land Cover Type (MCD12Q1 C5) product became available in 2008 to provide an update of the Collection 4 product (MOD12Q1 C4) (Friedl et al., 2010). This dataset consists of five different land cover classifications including the 17-class International Geosphere-Biosphere Programme (IGBP) classification (Loveland and Belward, 1997) and a 12-class PFT classification produced for each year from 2000 to present at $500 \mathrm{~m}$ resolution (Friedl et al., 2010). Compared to MOD12Q1 C4, the $\mathrm{C} 5$ product yields significant improvements in both spatial resolution $(500 \mathrm{~m}$ for $\mathrm{C} 5$ and $1000 \mathrm{~m}$ for $\mathrm{C} 4$ data) and classification accuracy (Friedl et al., 2010). The MODIS LAI product is also available as an 8-day composite at $1000 \mathrm{~m}$ resolution and has been widely used in land surface models. However, due to the presence of clouds, snow cover, and instrument problems, the MODIS LAI product produced considerable noise and gaps. To reduce the noise, the current CLM 4.0 PFT LAI parameters were derived by averaging high-quality MODIS LAI data during 2001-2003 onto coarser resolution $\left(0.5^{\circ}\right)$ grid cells, and partitioning the averaged LAI for each PFT. Yuan et al. (2011) presented a re-processed global MODIS LAI product from years 2000 to 2010 using a temporal spatial filter algorithm to improve the LAI data quality while preserving the spatial resolution. Compared to the current MODIS LAI data, it significantly removed unrealistic fluctuations and provided more accurate, spatiotemporally continuous and consistent LAI values. This improved LAI product is currently the most spatially and temporally complete LAI data that has been fully validated. With the most recent updated and improved land cover and vegetation products, it is feasible to regenerate land surface parameters for CLM 4.0 with higher resolution and better accuracy.

This study aims to develop new high-resolution global CLM 4.0 land surface parameters based on the best available MODIS land surface data, and presents an example application of the new parameters in regional modeling using the Weather Research and Forecasting (WRF) coupled with CLM (WRF-CLM) over the western US at $12 \mathrm{~km}$ resolution. Specifically, the new parameters generated include percentage of lake, wetland, urban and glacier, PFT fractional cover, and monthly PFT LAI and SAI, all at $0.05^{\circ}$ resolution. New parameters were compared against the current CLM 4.0 parameters globally and regionally, and the PFTs were further evaluated over the conterminous US (CONUS) domain using the 2006 National Land Cover Database (NLCD) data (http://www.mrlc.gov/) and the United States Department of Agriculture National Agriculture Statistics Service (USDA 
NASS) statistical report on US crop area (http://www.nass. usda.gov/).

\section{Method}

\subsection{New Plant Functional Types mapping}

The MCD12Q1 C5 PFT classifications for the year 2005 were directly used to determine seven PFTs including Needleleaf Evergreen trees, Needleleaf Deciduous trees, Broadleaf Evergreen trees, Broadleaf Deciduous trees, shrub, grass and crop for each $500 \mathrm{~m}$ pixel. The WorldClim 5 arcminute $\left(0.0833^{\circ}\right)$ (Hijmans et al., 2005) climatological global monthly surface air temperature and precipitation data was interpolated to $500 \mathrm{~m}$ grids and used to further reclassify the 7 PFTs into 15 PFTs in the tropical, temperate and boreal climate groups based on climate rules described by Bonan et al. (2002a). Similar to Lawrence and Chase (2007), fractions of $\mathrm{C} 3$ and $\mathrm{C} 4$ grasses were mapped based on the method presented in Still et al. (2003). Pixels with barren land and urban areas were reassigned to the bare soil class. The bare soil and the 15 PFTs in the $500 \mathrm{~m}$ grids were then aggregated to $0.05^{\circ}$ grids and the fractional cover of each PFT was calculated as the total area of the $500 \mathrm{~m}$ grids that were classified as this PFT over the area of the $0.05^{\circ}$ grid.

\subsection{New LAI and SAI mapping}

The new PFT LAI mapping was based on the improved MODIS LAI 8-day composite product reprocessed by Yuan et al. (2011) and the 15-PFT classification described above. First, the 1-km 8-day improved MODIS LAI for the year 2005 was used to calculate a mean monthly LAI that was then interpolated to a set of $500 \mathrm{~m}$ grids using Nearest Neighbour sampling method. Combined with the 15 PFTs resulted from the reclassification of the MCD12Q1 C5 product at a $500 \mathrm{~m}$ resolution, monthly LAI values for each PFT was determined. Finally, the PFT LAI was calculated by averaging LAIs for each PFT within the $0.05^{\circ}$ grids. It has been widely recognized that MODIS often underestimates LAI during the winter season at high latitudes (e.g. latitude $>60^{\circ} \mathrm{N}$ ) because of snow cover and low sun angles. To account for the underestimation, the evergreen phenology correction was performed following Lawrence and Chase (2007) so that LAI values of evergreen PFTs were only allowed to reach a minimum fraction of the annual maximum PFT LAI from the MODIS improved LAI product. The maximum PFT LAI value listed in Bonan et al. (2002a) was used to constrain the range of PFT LAIs. Monthly PFT SAI values were calculated following the same method described in Lawrence and Chase (2007) using the monthly PFT LAI values, the PFT percentage, and minimum PFT SAI values.

\subsection{Non-vegetated land cover mapping}

The distribution of global lakes was derived from the MCD12Q1 C5 IGBP classification of water bodies using the ESRI Data and Maps landmass boundaries (www.esri.com) to constrain water bodies to inland water only. The distribution of wetlands was derived from the MCD12Q1 IGBP classification of permanent wetlands, glacier from classification of snow and ice, and urban from classification of urban and built-up areas. All $500 \mathrm{~m}$ pixels were aggregated to $0.05^{\circ}$ grid cells to generate the fractional cover of lake, wetland, glacier and urban.

\subsection{Comparison of parameter development methods}

The source data that was used to generate the new highresolution land surface parameters and the CLM 4.0 land surface parameters are compared in Table 1 . The current CLM 4.0 PFT parameters generally relied on the MODIS VCF product to provide vegetated and non-vegetated land fraction information, and used the AVHRR Continuous Field Tree Cover data to further determine the fraction of trees with different leaf types and leaf longevity (Lawrence and Chase, 2007). The various data sources are at different spatial resolutions and represent land conditions spanning from 1992 to 2001. For example, the MODIS VCF dataset from Hansen et al. (2003) is at $500 \mathrm{~m}$ resolution representing the year 2001. The AVHRR Continuous Fields Tree Cover Project dataset is at $1 \mathrm{~km}$ resolution representing the year 1992-1993. The Willmott and Matsuura climate data (Willmott and Matsuura, 2000) used to break down the PFTs into different climate regions are at $0.5^{\circ}$ resolution. The global crop data represent the year 2000 (Ramankutty et al., 2008; Lawrence et al., 2011). Non-vegetated land cover parameters were also derived from various data sources and developed at $0.5^{\circ}$ resolution (Oleson et al., 2010). For the PFT LAIs, the current CLM 4.0 parameter made use of MODIS LAI from 2001 to 2003 to provide averaged monthly LAI to $0.05^{\circ}$ resolution and then disaggregate the LAI to each PFT based on the relative maximum PFT LAI values (Lawrence and Chase, 2006). The LAI parameter was then aggregated to a coarser $0.5^{\circ}$ resolution to reduce the noise (D. M. Lawrence, personal communication, 2012).

Briefly, our method differs from that used to develop the current CLM 4.0 parameters in three aspects. First, the new parameters were derived from MODIS land product with discrete land cover classifications rather than the land fraction information used by the current CLM 4.0 parameters. The underlying assumption of our method is that each $500 \mathrm{~m}$ pixel in the MODIS land cover product was exclusively covered by a single land cover type in each pixel. Second, the new parameters were consistently derived from MODIS products at the same spatial resolution for the same year rather than various data sources with information that spans 1991 to 2008 with no internal consistency by the current 
Table 1. Properties of new and CLM 4.0 land surface data.

\begin{tabular}{|c|c|c|c|c|c|c|}
\hline \multirow{2}{*}{ Surface data } & \multicolumn{2}{|c|}{ Resolution } & \multicolumn{2}{|c|}{ Source data } & \multicolumn{2}{|c|}{ Source date } \\
\hline & New & CLM 4.0 & New & CLM 4.0 & New & CLM 4.0 \\
\hline Glacier & $0.05^{\circ}$ & $0.5^{\circ}$ & MCD12Q1 PFT classification & IGBP DISCover & 2005 & 2000 \\
\hline Lake & $0.05^{\circ}$ & $0.5^{\circ}$ & $\begin{array}{l}\text { MCD12Q1 PFT classification, } \\
\text { ESRI landmass boundaries }\end{array}$ & $\begin{array}{l}1^{\circ} \text { by } 1^{\circ} \text { global } \\
\text { perennial freshwater lakes and } \\
\text { swamps/marshes }\end{array}$ & 2005 & 1991 \\
\hline Wetland & $0.05^{\circ}$ & $0.5^{\circ}$ & MCD12Q1 IGBP classification & $\begin{array}{l}1^{\circ} \text { by } 1^{\circ} \text { global } \\
\text { perennial freshwater lakes and } \\
\text { swamps/marshes }\end{array}$ & 2005 & 1991 \\
\hline Urban & $0.05^{\circ}$ & $0.5^{\circ}$ & MCD12Q1 PFT classification & $\begin{array}{l}\text { LandScan population density } \\
\text { dataset }\end{array}$ & 2005 & 2004 \\
\hline PFTs & $0.05^{\circ}$ & $0.5^{\circ}$ & $\begin{array}{l}\text { MCD12Q1 PFT classification, } \\
\text { WorldClim climate }\end{array}$ & $\begin{array}{l}\text { AVHRR continuous fields, } \\
\text { MODIS vegetation continuous } \\
\text { fields, Willmott and Matsuura } \\
\text { Climate, global agriculture } \\
\text { land based on Ramankutty et } \\
\text { al. (2008) }\end{array}$ & 2005 & $\begin{array}{l}\text { Mixed } \\
\text { years from } \\
1993 \text { to } \\
2001\end{array}$ \\
\hline LAI and SAI & $0.05^{\circ}$ & $0.5^{\circ}$ & $\begin{array}{l}\text { Continuous LAI improved from } \\
\text { MOD15A1 }\end{array}$ & MCD15A2 & 2005 & $2001-2003$ \\
\hline
\end{tabular}

CLM 4.0 parameters. The year 2005 was used to represent the current-day land cover condition. CLM 4.0 is capable of modeling land cover change in a transient mode. It diagnoses the change in area for PFTs at each model time step and performs mass and energy balance to represent the expansion and contraction of PFT area based on an annual time series of PFT distribution data sets (Oleson et al., 2010). In our study the CLM land surface parameters for the particular year of 2005 were developed to be compatible with this capability. Lastly and most importantly, the new parameters were all developed at higher resolution than the current CLM 4.0 parameters (Table 1).

\subsection{New parameter mapping evaluation}

The new land surface parameters, including PFTs and nonvegetated land fractional cover, were compared against the CLM 4.0 land surface parameters over the global land area and three specific regions: Boreal $\left(50^{\circ} \mathrm{N} \sim 70^{\circ} \mathrm{N}\right)$, Amazon $\left(80^{\circ} \mathrm{W} \sim 30^{\circ} \mathrm{W}, 20^{\circ} \mathrm{S} \sim 10^{\circ} \mathrm{N}\right)$, and Sahara and Arabia $\left(20^{\circ} \mathrm{W}-60^{\circ} \mathrm{E}, 15^{\circ} \mathrm{N}-35^{\circ} \mathrm{N}\right)$. In our study the default CLM 4.0 land surface parameters officially released with $\mathrm{CESM}$ at $0.5^{\circ}$ resolution were used for the comparison. The new PFT and non-vegetated land parameters at $0.05^{\circ}$ resolution were aggregated to $0.5^{\circ}$ grids to be comparable with the current CLM 4.0 parameters. Global maps of the new and CLM 4.0 land surface parameters were generated to demonstrate the spatial similarities and differences between the two sets of parameters. Overall average values of percentage of PFTs and non-vegetated land cover were also compared with the current CLM 4.0 parameters globally and regionally.
The number of PFTs per grid of both the new and current CLM 4.0 parameters were mapped and compared in order to evaluate the effect of the higher resolution in the new parameters.

To further assess the accuracies of PFTs, PFTs from both the new and CLM 4.0 land parameters were compared with the 2006 NLCD and the 2007 NASS crop statistical data over CONUS. The 2006 NLCD is a 16-class land cover data over CONUS at a spatial resolution of 30 meters which was produced primarily on the classification of Landsat Enhanced Thematic Mapper+ (ETM+) circa 2006 satellite data (Fry et al., 2011). The USDA NASS provides agriculture statistics every five years for US states and counties, and include crop type, crop area, production, etc. (http://www.nass.usda.gov/). Considering the difference in the CLM PFT and NLCD classification scheme, the land cover classes in the new PFT parameters, CLM 4.0 PFT parameters and the NLCD were reclassified into five general land cover types, i.e. bare soil, trees, shrub, grass, and crops, based on the recoding method in Table 2. Because the "bare" class in the CLM PFT parameters was defined as any non-vegetated area including bare land and open water, the open water areas were eliminated from the "bare" parameter using the new and CLM 4.0 lake percentage parameter, respectively for the new PFT parameters and CLM 4.0 PFT parameters. The reclassified NLCD $30 \mathrm{~m}$ land cover was re-projected and then aggregated to a $0.5^{\circ}$ grid resolution. The percentages of bare soil, trees, shrub, grass and cropland were calculated for each $0.5^{\circ}$ grid and then compared with the new and CLM 4.0 PFT parameters over CONUS. In our study, the report on total non-woody 
Table 2. Reclassification of new, CLM4.0 PFT parameters and NLCD land cover classes.

\begin{tabular}{|c|c|c|}
\hline $\begin{array}{l}\text { CLM } \\
\text { PFTs }\end{array}$ & $\begin{array}{l}\text { NLCD Land-Cover } \\
\text { Land-Cover Classes }\end{array}$ & $\begin{array}{l}\text { Generalized land } \\
\text { cover classes }\end{array}$ \\
\hline $\begin{array}{l}\text { Needleleaf Evergreen Temperate trees; } \\
\text { Needleleaf Evergreen Boreal trees; } \\
\text { Needleleaf Deciduous Boreal trees; } \\
\text { Broadleaf Evergreen Tropical trees; } \\
\text { Broadleaf Evergreen Temperate trees; } \\
\text { Broadleaf Deciduous Tropical trees; } \\
\text { Broadleaf Deciduous Boreal trees }\end{array}$ & $\begin{array}{l}\text { Evergreen forest; Deciduous forest; } \\
\text { Mixed forest; Woody wetland }\end{array}$ & Tree \\
\hline $\begin{array}{l}\text { Broadleaf Evergreen Temperate shrubs; } \\
\text { Broadleaf Deciduous Temperate } \\
\text { shrubs; Broadleaf Deciduous Boreal } \\
\text { shrubs }\end{array}$ & Dwarf Scrub; Shrub/Scrub & Shrub \\
\hline $\begin{array}{l}\text { C3 Arctic grass; C3 non-Arctic grass, } \\
\text { C4 grass }\end{array}$ & $\begin{array}{l}\text { Grassland/Herbaceous; Pasture/Hay; } \\
\text { Developed, open space; Developed, } \\
\text { low intensity; Herbaceous wetland }\end{array}$ & Grass \\
\hline Crop & Cultivated crops & Crop \\
\hline $\begin{array}{l}\text { Bare soil excluding open water in CLM } \\
\text { surface parameter }\end{array}$ & $\begin{array}{l}\text { Barren land; Developed, medium } \\
\text { intensity; Developed, high intensity; } \\
\text { Perrennial Ice/Snow }\end{array}$ & Bare ground \\
\hline
\end{tabular}

crop acreage in the year 2007 was used to provide a reference crop area for comparison with the new and CLM 4.0 estimated cropland over the US.

Seasonal average LAI and SAI were calculated by combining the composition of PFTs and monthly PFT LAI and SAI for both the new and current CLM 4.0 parameters. Spatial and statistical comparison of LAI and SAI from both parameter sets over global and regional land areas was performed. In addition, LAI values were also evaluated against the MODIS improved LAI product at the global extent. Monthly PFT LAIs were calculated for the new and current CLM 4.0 parameters by averaging LAI values for each PFT across the Northern and Southern Hemisphere, respectively. Plots of monthly PFT LAIs were used to assess the seasonal cycles of individual PFT LAI.

\subsection{Regional climate simulation}

CLM has been used as the land surface model in the CCSM for global climate modeling since CCSM 1.0 was developed in the mid-1990s. CLM has also been coupled to the WRF model (Skamarock et al., 2008) to simulate the regional climate of the western US (Leung et al., 2006; Jin et al., 2010; Subin et al., 2011). In the previous implementation of WRFCLM, CLM was coupled to WRF through a subroutine call from WRF to CLM as one of a few options for land surface modeling. Because the CLM surface parameters were only available at $0.5^{\circ}$ resolution, Subin et al. (2011) used various land surface datasets developed for WRF to prescribe surface parameters for WRF-CLM. For example, they used a fixed mapping from WRF's 24 US Geological Survey (USGS) land-use categories to groups of up to 4 of CLM's 17 PFTs. Monthly LAI was prescribed for each PFT, so LAI varied with PFT but not geographically. These approaches did not take advantage of more detailed surface data normally prescribed in CLM for modeling biophysical processes.

More recently, through the development of the Regional Arctic Climate System Model (RACM) (Maslowski et al., 2011), WRF has been implemented as part of CCSM to make use of the CCSM flux coupler for coupling earth system components. Using RACM, we have coupled WRF with CLM using the flux coupler for exchange of surface fluxes and atmospheric and land surface states. A simulation has been configured for the western US at a $12 \mathrm{~km}$ grid resolution. To take full advantage of the high-resolution domain, the new $0.05^{\circ}$ resolution CLM surface parameters described above were used to specify non-vegetated land cover, PFTs, LAI, and SAI. Soil texture was obtained from the WRF $1 \mathrm{~km}$ resolution soil data derived from STATSGO. Other surface data including soil color and soil organic matter were derived from CLM 4.0 default data provided with CESM (http://www.cesm.ucar.edu/models/cesm1.0/clm/).

Since the western US WRF domain was defined using a Lambert Conformal projection with a fixed distance of $12 \mathrm{~km}$ between neighboring grid cells, the model grids were shapedistorted when projected to a regular latitude-longitude geographic coordinate system, which is used by the CLM land surface data. Although the existing WRF Preprocessing System (WPS) provides several interpolation options such as nearest neighbor, four-point bilinear, four-point simple 
Table 3. Average global and regional PFT composition*.

\begin{tabular}{|c|c|c|c|c|c|c|c|c|}
\hline \multirow{2}{*}{ PFT } & \multicolumn{2}{|c|}{ All land } & \multicolumn{2}{|c|}{ Amazon } & \multicolumn{2}{|c|}{ Boreal } & \multicolumn{2}{|c|}{ Sahara \& Arabia } \\
\hline & CLM 4.0 & New (Diff) & CLM 4.0 & New (Diff) & CLM 4.0 & New (Diff) & CLM 4.0 & New (Diff) \\
\hline Bare & 33.5 & $24.7(-9.2)$ & 3.8 & $2.4(-1.4)$ & 12.0 & $6.1(-5.9)$ & 87.8 & $78.3(-9.5)$ \\
\hline Ndl Evg Tmp & 3.0 & $2.2(-0.8)$ & 0.0 & $0.4(+0.4)$ & 2.7 & $4.0(+1.3)$ & 0.1 & $0.0(-)$ \\
\hline Ndl Evg Borl & 6.4 & $5.2(-1.2)$ & 0.0 & $0.2(+0.2)$ & 29.0 & $21.0(-8.0)$ & 0.0 & $0.0(-)$ \\
\hline Ndl Dec Borl & 1.0 & $2.3(+1.3)$ & 0.0 & $0.1(+0.1)$ & 4.9 & $10.6(+5.8)$ & 0.0 & $0.0(-)$ \\
\hline Brd Evg Trop & 8.7 & $9.4(+0.7)$ & 49.8 & $52.3(+2.5)$ & 0.0 & $0.0(-)$ & 0.0 & $0.0(-)$ \\
\hline Brd Evg Tmp & 1.4 & $1.6(+0.2)$ & 1.7 & $1.1(-0.6)$ & 0.0 & $0.4(+0.4)$ & 0.0 & $0.0(-)$ \\
\hline Brd Dec Trop & 5.1 & $2.8(-2.3)$ & 14.4 & $5.8(-8.6)$ & 0.0 & $0.0(-)$ & 0.4 & $0.4(-)$ \\
\hline Brd Dec Tmp & 3.3 & $2.5(-0.8)$ & 0.2 & $0.1(-0.1)$ & 1.7 & $1.8(+0.1)$ & 0.0 & $0.0(-)$ \\
\hline Brd Dec Borl & 1.2 & $0.9(-0.3)$ & 0.0 & $0.0(-)$ & 3.9 & $2.4(-1.5)$ & 0.0 & $0.0(-)$ \\
\hline Shr Evg Tmp & 0.1 & $0.7(+0.6)$ & 0.0 & $0.1(+0.1)$ & 0.0 & $0.3(+0.3)$ & 0.0 & $0.6(+0.6)$ \\
\hline Shr Dec Tmp & 3.8 & $11.2(+7.4)$ & 2.3 & $6.5(+4.2)$ & 0.1 & $0.3(+0.2)$ & 1.7 & $9.9(+8.2)$ \\
\hline Shr Dec Borl & 5.4 & $6.7(+1.3)$ & 1.0 & $0.5(-0.5)$ & 24.0 & $39.3(+15.3)$ & 0.0 & $0.0(-)$ \\
\hline Grs C3 Arctic & 2.9 & $3.1(+0.2)$ & 0.6 & $0.8(+0.2)$ & 9.9 & $9.1(-0.8)$ & 0.0 & $0.0(-)$ \\
\hline Grs C3 & 8.2 & $6.7(-1.5)$ & 5.9 & $3.0(-2.9)$ & 4.8 & $4.1(-0.7)$ & 1.2 & $0.4(-0.8)$ \\
\hline Grs C4 & 7.5 & $8.6(+1.1)$ & 17.1 & $22.1(+4.4)$ & 0.0 & $0.1(+0.1)$ & 5.8 & $8.6(+3.8)$ \\
\hline Crop & 8.5 & $11.1(+2.6)$ & 3.0 & $4.5(+1.5)$ & 7.0 & $10.2(+3.2)$ & 2.9 & $1.8(-1.1)$ \\
\hline
\end{tabular}

* Differences between new parameters and CLM 4.0 parameters are shown in brackets, with a dash indicating no change. Abbreviation: Ndl Evg Tmp = Needleleaf Evergreen Temperate trees; Ndl Evg Borl = Needleleaf Evergreen Boreal trees; Ndl Dec Borl= Needleleaf Deciduous Boreal trees; Brd Evg Trop = Broadleaf Evergreen Tropical trees; Brd Evg Tmp = Broadleaf Evergreen Temperate trees; Brd Dec Trop = Broadleaf Deciduous Tropical trees; Brd Dec Tmp = Broadleaf Deciduous Temperate trees; Brd Dec Borl = Broadleaf Deciduous Boreal trees; Shr Evg Tmp = Broadleaf Evergreen Temperate shrubs; Shr Dec Tmp = Broadleaf Deciduous Temperate shrubs; Shr Dec Borl = Broadleaf Deciduous Boreal shrubs; Grs C3 Arctic = C3 Arctic grass; Grs C3 = C3 non-Arctic grass; Grs C4 = C4 grass.

or weighted average, the WPS is not designed to generate land surface data for CLM. Moreover, the WPS interpolation methods are not accurate, especially for continuous fractional data. In this study, we developed an interpolation method to map the $0.05^{\circ} \mathrm{CLM}$ land surface data onto the WRF model grids based on an area-weighted average approach. For each WRF model grid, the method initially finds the intersecting CLM grids by determining whether one or more corners of a CLM grid are inside the WRF model grid. Next, each of the intersecting CLM grids is divided into $100 \times 100$ subgrids with a regular latitude/longitude interval. The total area of the subgrid whose center point is inside the WRF model grid is calculated and its proportion to the WRF model grid area is used as a weight for the intersecting CLM grid. The weighted average of all intersecting CLM grid attributes (e.g. fractional land cover, PFTs, LAI, etc.) is assigned to the WRF model grid.

A one-year simulation was performed from 1 October 2003-30 September 2004, with WRF initial and lateral boundary conditions obtained from the North American Regional Reanalysis (NARR) at a $32 \mathrm{~km}$ grid resolution (http://www.emc.ncep.noaa.gov/mmb/rreanl/). The NARR soil moisture and temperature at $0 \mathrm{Z}$ on 1 October 2003 was re-gridded to the WRF grid bi-linearly using the WPS, and vertically interpolated linearly to obtain CLM soil moisture and temperature profiles for model initialization.

\section{Results}

\subsection{New Plant Functional Type parameters}

Table 3 and Fig. 1 illustrate the spatial and statistical differences between the new and CLM 4.0 PFT parameters. Bare soil dominates the global land coverage. However, there is a large difference in bare soil between the two datasets. For the new parameters, the bare soil percentage decreased to $24.7 \%$ from $33.5 \%$ found in the CLM 4.0 parameters (Table 3); areas of change are found mainly in the high latitude areas of North America, western US, South Africa and central Australia, where the new parameters show significantly increased percentage of shrub coverage over bare soil (Figs. 1a and b, $2 \mathrm{a}$ and $\mathrm{b}$ ).

Figure 1c and d show similar spatial distribution of needleleaf trees in the new and CLM 4.0 PFT parameters, except that there is greater coverage in southeast US and far eastern Russia in CLM 4.0. Globally, both Needleleaf Evergreen Temperate trees and Needleleaf Evergreen Boreal trees have decreased coverage in the new parameters compared to CLM 4.0 (2.2\% compared to $3.0 \%, 5.2 \%$ compared to $6.4 \%$, respectively), but the Needleleaf Deciduous Boreal trees have increased coverage (2.3\% compared to $1.0 \%)$. Regional statistics show that the differences are mainly in the boreal region, which has substantially lower coverage of Needleleaf Evergreen Boreal trees $(21.0 \%$ compared to $29.0 \%$ ) but greater coverage of Needleleaf Deciduous Boreal trees (10.6\% compared to $4.9 \%)$ and Needleleaf Evergreen Temperate trees ( $4.0 \%$ compared to $2.7 \%$ ). Interestingly, in 
(a) New bare soil

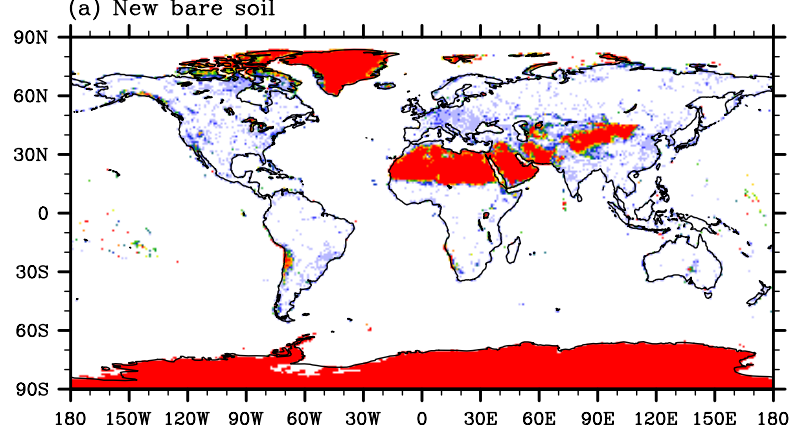

$180150 \mathrm{~W} 120 \mathrm{~W} 90 \mathrm{~W} 60 \mathrm{~W} 30 \mathrm{~T}$
(c) New Needleleaf trees

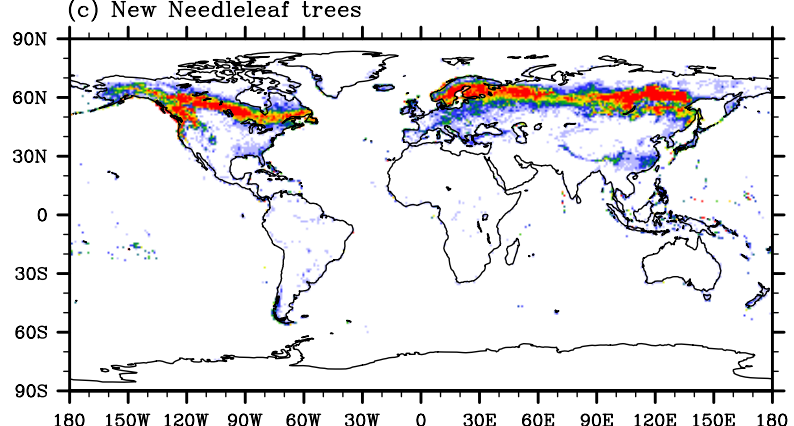

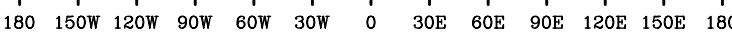
(e) New Broadleaf evergreen trees

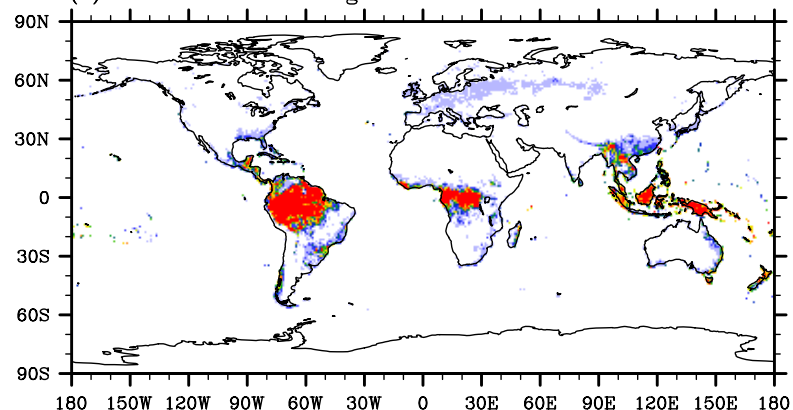

(g) New Broadleaf deciduous tree

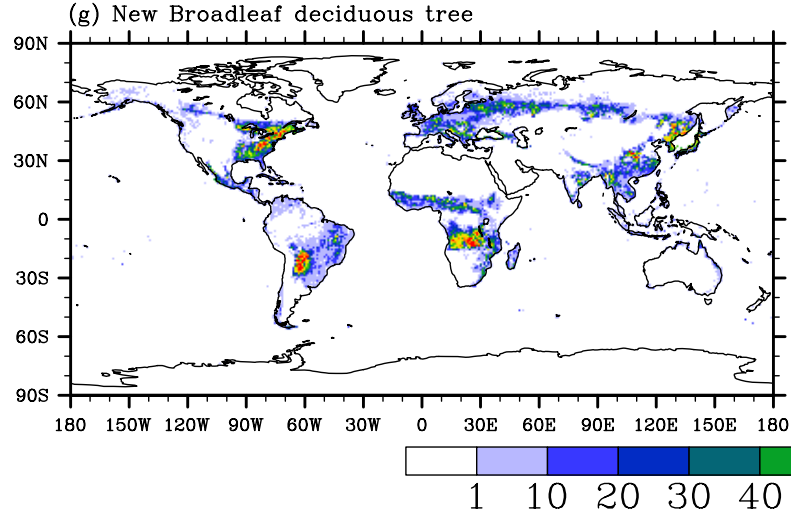

(b) CLM 4.0 bare soil

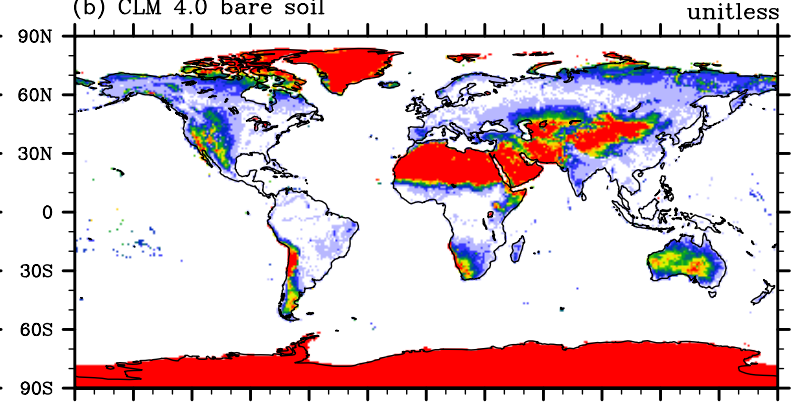

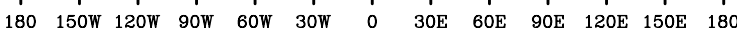

(d) CLM 4.0 Needleleaf trees

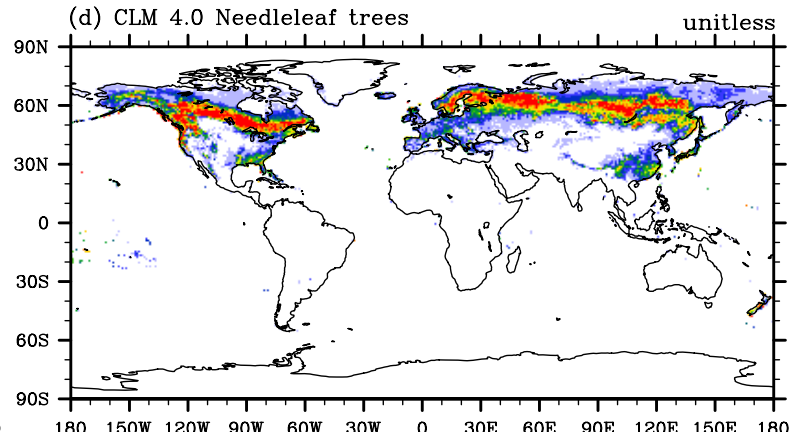

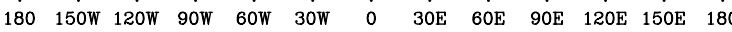

(f) CLM 4.0 Broadleaf evergreen trees

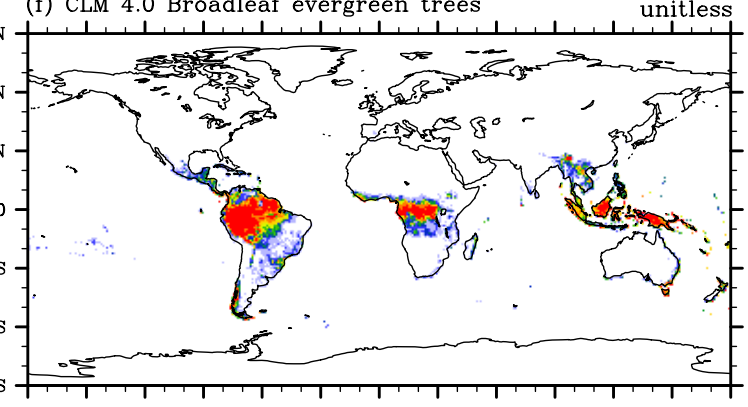

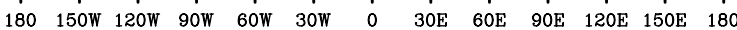

(h)CLM 4.0 Broadleaf deciduous tree unitless

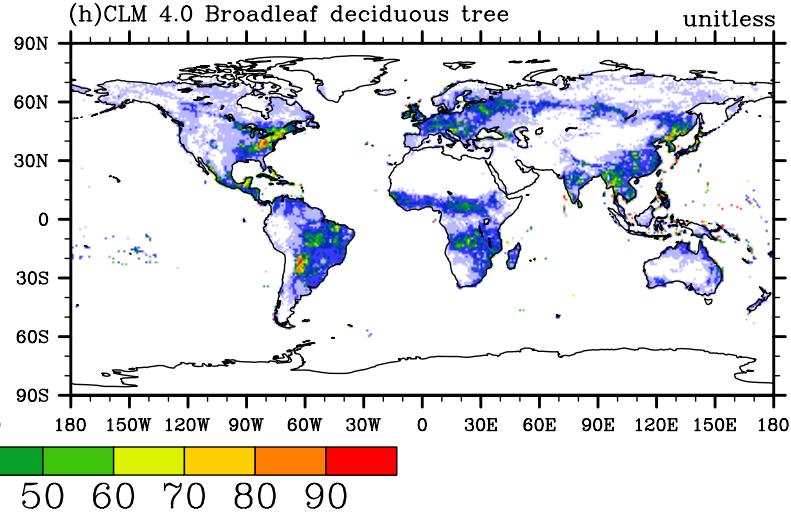

Fig. 1. Global distribution of bare soil, needleleaf trees, broadleaf evergreen trees and broadleaf deciduous trees for new and CLM 4.0 PFT parameters. (a) New bare soil; (b) CLM 4.0 bare soil; (c) New Needleleaf trees; (d) CLM 4.0 Needleleaf trees; (e) New Broadleaf evergreen trees; (f) CLM 4.0 Broadleaf evergreen trees; (g) New Broadleaf deciduous trees; (h) CLM 4.0 Broadleaf deciduous trees.

the Amazon region, there are $0.4 \%$ Needleleaf Evergreen Temperate trees in the new data that are not found in the CLM 4.0 parameters. No needleleaf trees are found in the Sahara and Arabia region for either set of parameters.
Broadleaf Evergreen trees are mostly distributed in the Amazon rainforest, central Africa and Southeast Asia in both the new and CLM 4.0 PFT parameters. From Fig. 1e and $\mathrm{f}$, the new parameters have increased coverage in the areas of southern China, Europe and western Russia, where no 
significant amount (less than $1 \%$ ) of Broadleaf Evergreen trees are found in CLM 4.0 parameters. Across all lands, both Broadleaf Evergreen Tropical trees and Broadleaf Evergreen Temperate trees have an increased percentage in the new parameters $(9.4 \%$ compared to $8.7 \%$ and $1.6 \%$ compared to $1.4 \%$, respectively). The Amazon region had increased Broadleaf Evergreen Tropical trees $(52.3 \%$ compared to $49.8 \%$ ) but decreased Broadleaf Evergreen Temperate trees $(1.1 \%$ compared to $1.7 \%)$. The Boreal region had $0.4 \%$ of Broadleaf Evergreen Temperate trees in the new parameters while no such trees are found in CLM 4.0 parameters.

Figure $1 \mathrm{~g}$ and $\mathrm{h}$ show that the new parameters produced less spatial coverage of Broadleaf Deciduous trees than the current CLM 4.0 parameters, with a lower percentage across all land in Broadleaf Deciduous Tropical trees (2.8\% compared to $5.1 \%$ ), Broadleaf Deciduous Temperate trees (2.5\% compared to $3.3 \%$ ), and Broadleaf Deciduous Boreal trees (0.9\% compared to $1.2 \%)$. Regional analysis showed that the Amazon region has a large decrease of Broadleaf Deciduous Tropical trees (5.8\% compared to $14.4 \%$ ) and a small decrease of Broadleaf Deciduous Temperate trees $(0.1 \%$ compared to $0.2 \%$ ). The Boreal region has a large decrease in Broadleaf Deciduous Boreal trees $(2.4 \%$ compared to $3.9 \%)$.

Large differences are found in shrub coverage between the new and CLM 4.0 parameters (Fig. 2a and b). The new parameters produced a large concentrated distribution of shrub at the high latitude areas of North America, Mexico, South Africa and Australia, while the CLM 4.0 parameters show much less shrub percentage over these same areas. Globally, the new parameters have a large increase of Broadleaf Deciduous Temperate shrubs (11.2\% compared to $3.8 \%)$, Broadleaf Evergreen Temperate shrubs (0.7\% compared to $0.1 \%)$ and Broadleaf Deciduous Boreal shrubs (6.7\% compared to $5.4 \%$ ). In the Amazon region there is a large increase of Broadleaf Deciduous Temperate shrubs $(6.5 \%$ compared to $2.3 \%$ ) and a decrease of Broadleaf Deciduous Boreal shrubs $(0.5 \%$ compared to $1.0 \%)$. The Boreal region has a large increase of Broadleaf Deciduous Boreal shrubs (39.3\% compared to $24.0 \%$ ) and an increase of Broadleaf Evergreen Temperate $(0.3 \%$ compared to $0 \%)$ and Broadleaf Deciduous Temperate shrubs ( $0.3 \%$ compared to $0.1 \%)$. The Sahara and Arabia region has a large increase of Broadleaf Deciduous Temperate shrubs (9.9\% compared to $1.7 \%$ ), and an increase of Broadleaf Evergreen Temperate shrubs $(0.6 \%$ compared to $0 \%$ ).

Global distribution of grass shows less coverage of C3 grass in the new parameters at the high latitude areas, US Great Plains, and South Africa, but shows greater concentration in the Northwest US and around the fringes of Great Tibet (Fig. 2c and d). The distribution pattern of $\mathrm{C} 4$ grass is similar between the new and CLM 4.0 parameters, except there is an increased concentration of $\mathrm{C} 4$ grass in Brazil, Sahel, southern Africa and northern Australia. Globally, the new parameters have a small increase of $\mathrm{C} 3$ Arctic grass ( $3.1 \%$ compared to $2.9 \%$ ), a decrease of $\mathrm{C} 3$ non-Arctic grass (6.7\% compared to $8.2 \%$ ), and a small increase of $\mathrm{C} 4$ grass ( $8.6 \%$ compared to $7.5 \%$ ). In the Amazon region there is a decrease of $\mathrm{C} 3$ non-Arctic grass (3.0\% compared to $5.9 \%$ ) and an increase of $\mathrm{C} 4$ grass (22.1\% compared to $17.1 \%)$. In the Boreal region, both $\mathrm{C} 3$ Arctic and non-Arctic grass have decreased contribution (9.1\% compared to $9.9 \%$ and $4.1 \%$ compared to $4.8 \%$ ), and $\mathrm{C} 4$ grass has a small increased contribution $(0.1 \%$ compared to $0 \%)$. The Sahara and Arabia region has a decrease of $\mathrm{C} 3$ grass $(0.4 \%$ compared to $1.2 \%)$, but a large increase of $\mathrm{C} 4$ grass ( $8.6 \%$ compared to $5.8 \%$ ).

Across the globe, a considerable increase of cropland is reported in the new parameters (11.1\% compared to $8.5 \%)$. The global distribution shows that the new parameters have a greater concentration of crop in the Midwest US, Europe, India and eastern China, but less crop coverage in eastern Africa. Regional analysis shows that the new parameters have a relatively large increase of crop in the Amazon (4.5\% compared to $3.0 \%$ ) and Boreal (10.2\% compared to $7.0 \%$ ), and a large decrease of crop in the Sahara and Arabia (1.8\% compared to $2.9 \%$ ).

Figure $3 \mathrm{a}$ and $\mathrm{b}$ shows the distribution of the number of PFTs within each $0.5^{\circ} \times 0.5^{\circ}$ grid cell for the new and CLM 4.0 parameters. The new parameters generally produce more PFT classes per grid or larger subgrid variability of PFTs, especially in temperate climate such as the eastern US, Europe, and eastern China. However, the new parameters have a lower number of PFTs in the higher latitude areas of the Northern Hemisphere $\left(>60^{\circ} \mathrm{N}\right)$ and semi-arid areas such Western Australia, where shrub dominates in the new parameters while CLM 4.0 indicates a mix of shrub and bare soil. The latitudinal distribution of the average number of PFTs shows a similar pattern in the two datasets (Fig. 3c). Both parameters have high vegetation abundance at the mid-latitude zones $\left(40^{\circ} \mathrm{N} \sim 60^{\circ} \mathrm{N}\right.$, $40^{\circ} \mathrm{S} \sim 60^{\circ} \mathrm{S}$ ), and low vegetation abundance at high latitude zones $\left(60^{\circ} \mathrm{N} \sim 90^{\circ} \mathrm{N}, 60^{\circ} \mathrm{S} \sim 90^{\circ} \mathrm{S}\right)$. In the low to midlatitude zone $\left(40^{\circ} \mathrm{N} \sim 40^{\circ} \mathrm{S}\right)$, both the new and CLM 4.0 parameters have a decreasing number of PFTs around the equator, $20^{\circ} \mathrm{N}$, and $30^{\circ} \mathrm{S}$, and an increasing number of PFTs around $10^{\circ} \mathrm{N}$ and $10^{\circ} \mathrm{S}$. Except between $15^{\circ} \mathrm{S}$ and $35^{\circ} \mathrm{S}$, the new parameters produced more average PFTs classes in each grid than the CLM 4.0 parameters across all latitudes.

\subsection{Evaluation of Plant Functional Type parameters over CONUS}

From the analyses discussed above, the US is one of the regions where large differences are found in the spatial distribution of PFTs between the two datasets. To assess the relative merits of the datasets, PFT parameters from the new and CLM 4.0 datasets are evaluated using the 2006 NLCD data. Figure 4 shows the spatial patterns of land cover classes from the new, CLM 4.0, and NLCD parameters. Bare soil 
(a) New shrub

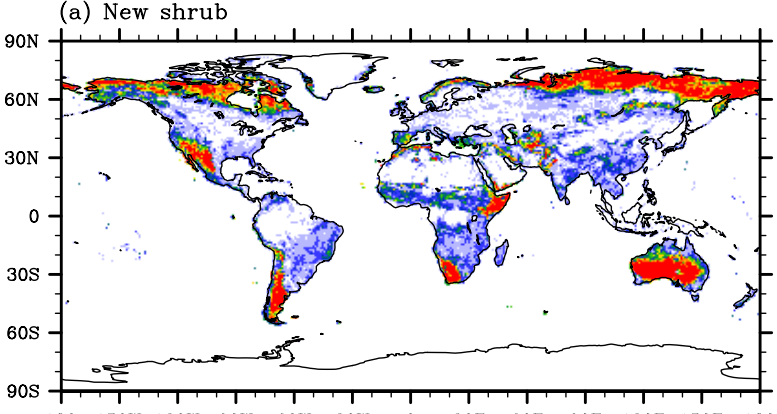

180 150W 120W 90W 60W 30W 0 30E $60 \mathrm{E}$ 90E $120 \mathrm{E} \quad 150 \mathrm{E} \quad 180$ (c) New C3 grass

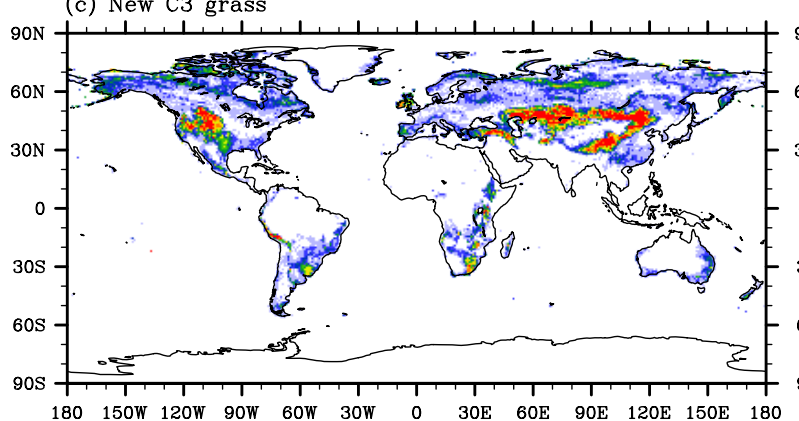

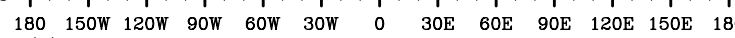
(e) New C4 grass

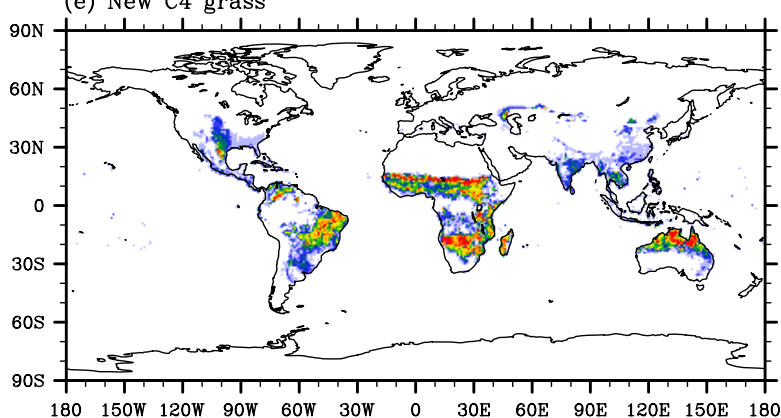

(g) New Crop

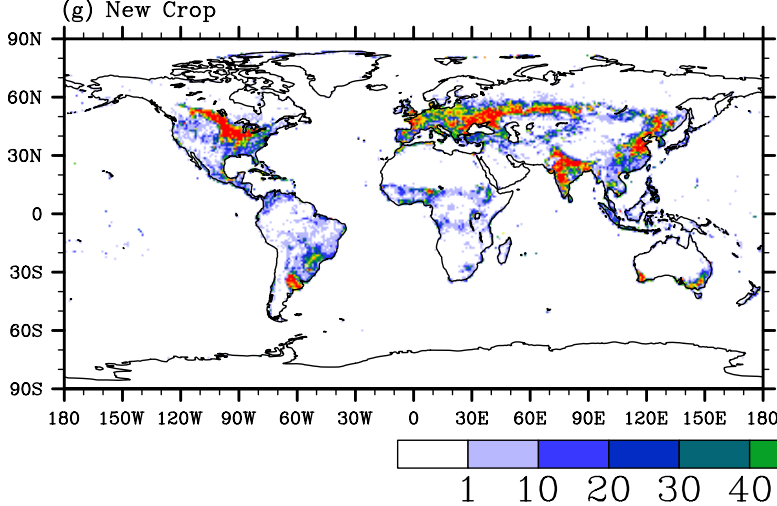

(b) CLM 4.0 shrub

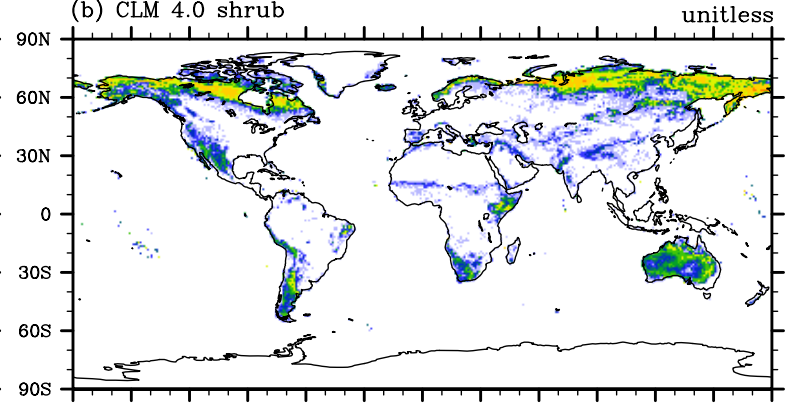

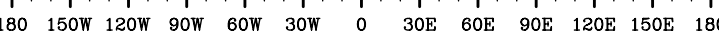

(d) CLM $4.0 \mathrm{C} 3$ grass

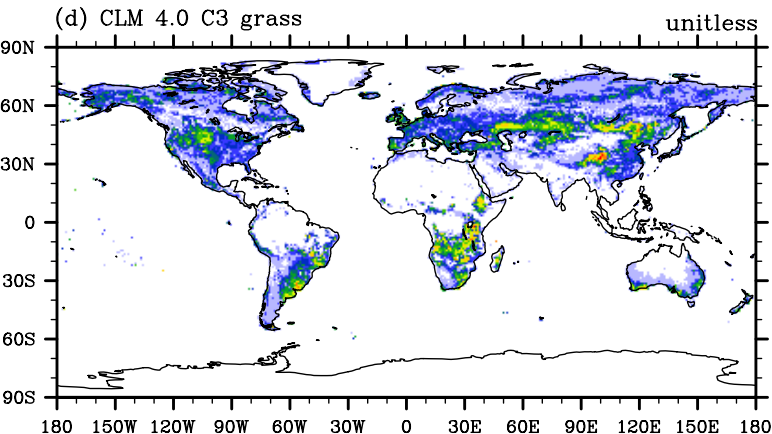

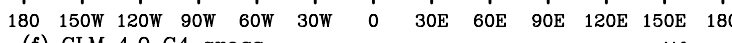
(f) CLM $4.0 \mathrm{C} 4$ grass

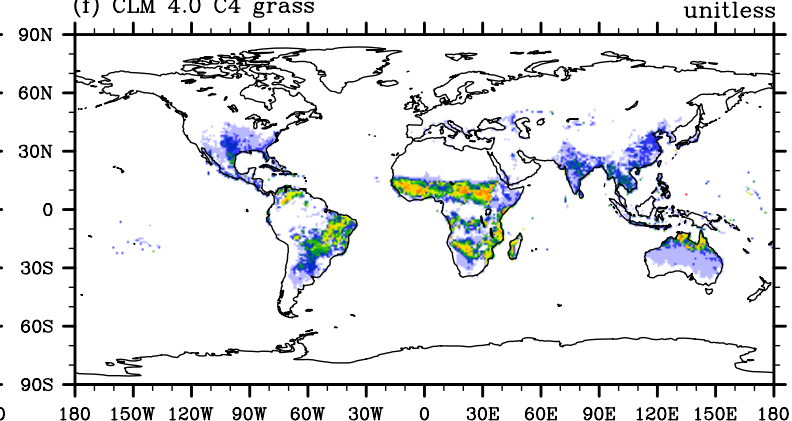

(h) CLM 4.0 Crop

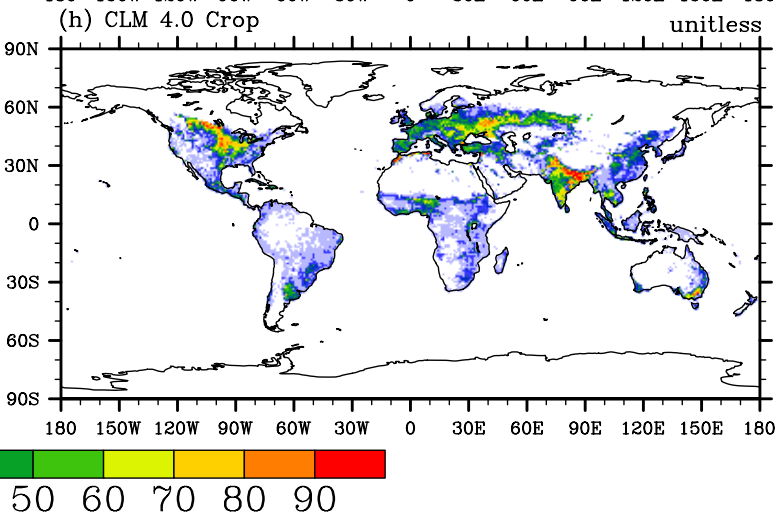

Fig. 2. Global distribution of shrub, C3 grass, C4 grass and crop for new and CLM 4.0 PFT parameters. (a) New shrub; (b) CLM 4.0 shrub; (c) New C3 grass; (d) CLM 4.0 C3 grass; (e) New C4 grass; (f) CLM 4.0 C4 grass; (g) New crop; (h) CLM 4.0 Crop.

in NLCD data is mainly concentrated in the arid regions of western US, with some coverage scattered in other parts of US (Fig. 4c). The new PFT parameters show a similar spatial pattern (Fig. 4a), but CLM 4.0 significantly overestimates bare soil coverage in the mid-western and western US and has a much lower contribution in the eastern US.
Over CONUS, the area covered by bare soil represented by CLM 4.0 is considerably higher than both the new PFT and NLCD parameters (14.8\% compared to $2.7 \%$ in new PFT parameters and $2.0 \%$ in NLCD).

The spatial coverage of trees is similar between CLM 4.0 and NLCD, with CLM 4.0 slightly overestimating trees over 
(a) New PFTs

(b) CLM 4.0 PFTs
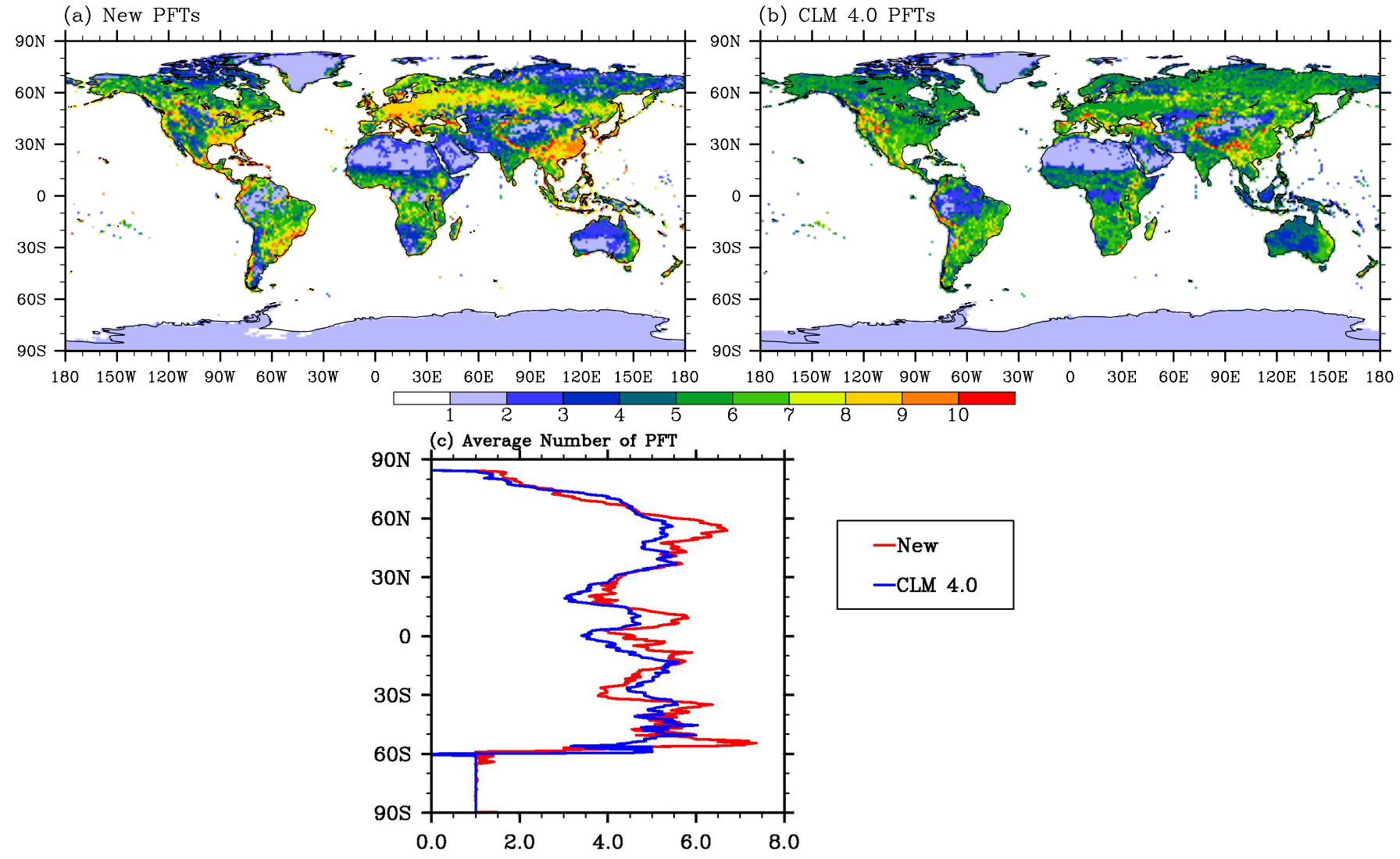

Fig. 3. (a) and (b): Global distribution of number of PFTs; (c) Latitude distribution of average number of PFTs.

Table 4. Percentage of land cover types for new, CLM4 and reference data over CONUS.

\begin{tabular}{lrrrll}
\hline Data & Trees & Shrub & Grassland & Cropland & Bare soil \\
\hline CLM 4.0 & 31.5 & 4.8 & 25.1 & 20.5 & $\begin{array}{l}14.8 \\
\text { Over } 85 \% \text { of } \\
\text { bare soil: } 3.5\end{array}$ \\
New & & & & & 2.7 \\
NLCD & 25.2 & 14.8 & 28.3 & 25.0 & 2.0 \\
USDA NASS & NA & NA & NA & Year 2007: 20.3 & NA \\
& & & & Year 2002: 21.7 & \\
\hline
\end{tabular}

CONUS (31.5\% compared to $28.8 \%)$. The new parameters have similar spatial distribution of trees in eastern and northwestern US, but they have much less coverage in the Midwestern US, which led to an overall underestimation of tree percentage over CONUS (25.2\% compared to $28.8 \%$ ). Shrub distribution is similar between the new PFT parameters and NLCD data: shrubs are mainly concentrated in the southwestern US, with some coverage in the southeastern US; however, shrubs in CLM 4.0 are limited to the western US with much lower coverage, and no shrub $(<1 \%)$ cover found in the east. These result in a large underestimation of shrubs over CONUS in CLM 4.0 (4.8\% compared to
$21.4 \%$ ). The underestimation has been significantly alleviated in the new parameters.

Over CONUS, the new parameters have a relatively accurate estimation of grassland area $(28.3 \%$ compared to $28.5 \%$ ), while the current CLM 4.0 parameters have a slight underestimation $(25.1 \%$ compared to $28.5 \%)$. However, the spatial distribution of grassland is very different between the new PFT parameters and the NLCD data. While both CLM 4.0 and NLCD have grassland distributed across CONUS, the new parameters have grassland concentrated in the West with little coverage in the northern Great Plains, Midwest, and eastern US. Instead, the latter regions have 
(a) New bare soil

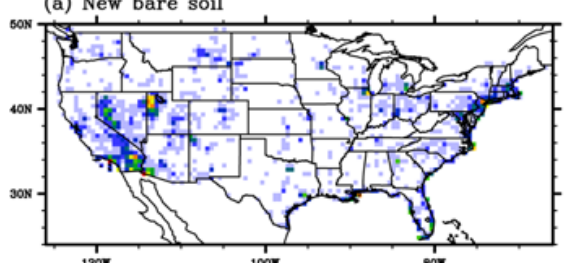

(d) New trees

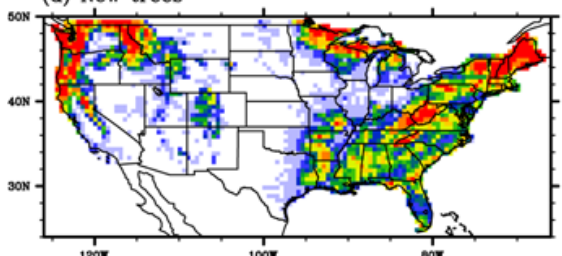

(g) New shrub

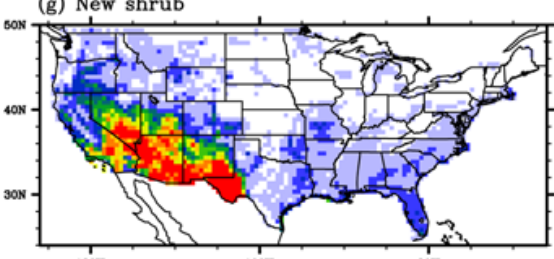

(j) New grass

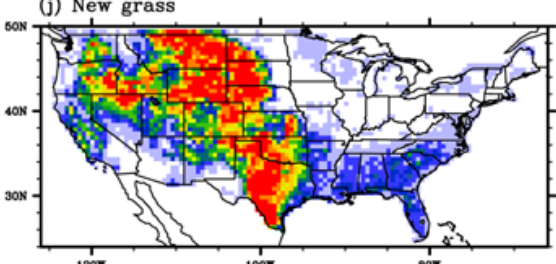

(m) ${ }^{120 \%}$ New crop (b) CLM 4.0 bare soil

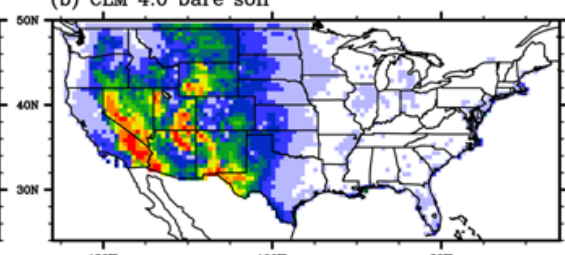

(e) CLM 4.0 trees

(c) NLCD bare soil

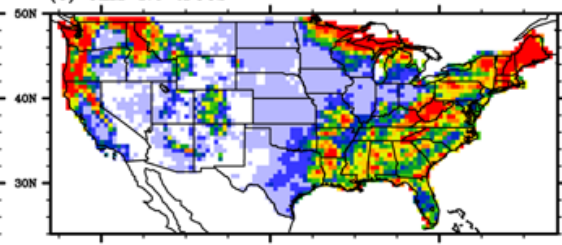

(h) ${ }^{120 \%}$ CLM 4.0 shrub

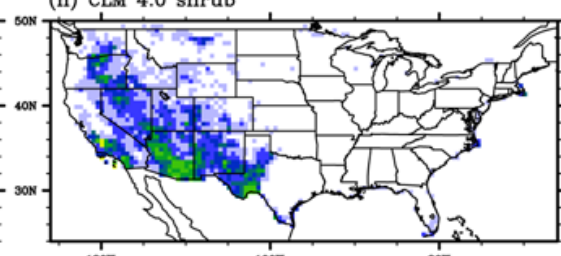

(k) CLM 4.0 grass

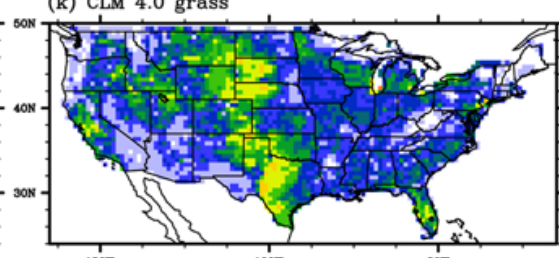

(n) ${ }^{1200}$ CLM 4.0 crop

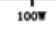

Bo:

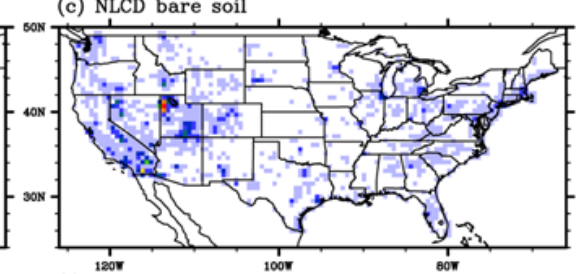

(f) $\stackrel{120 \%}{\text { NLCD trees }}$

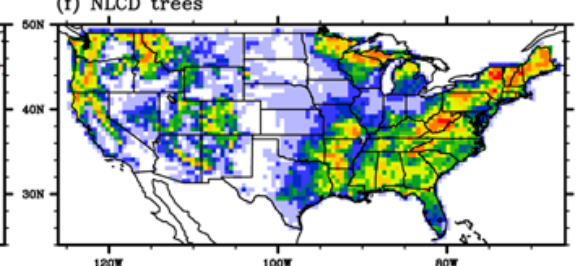

(i) ${ }^{120 \%}$

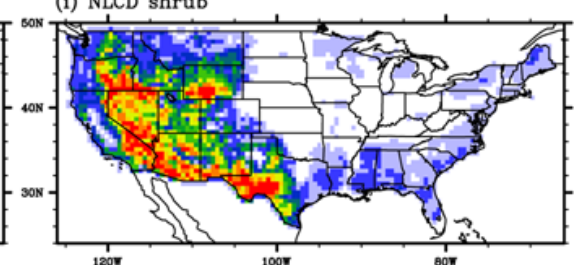

(1) ${ }^{120 \%}$ NLCD grass

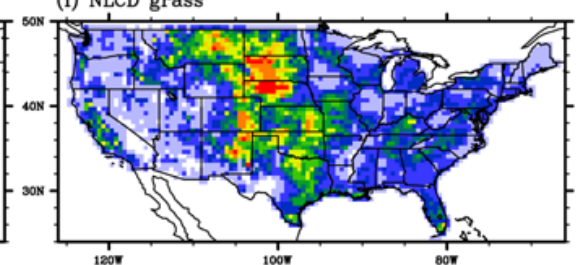

(o) ${ }^{120 \%}$
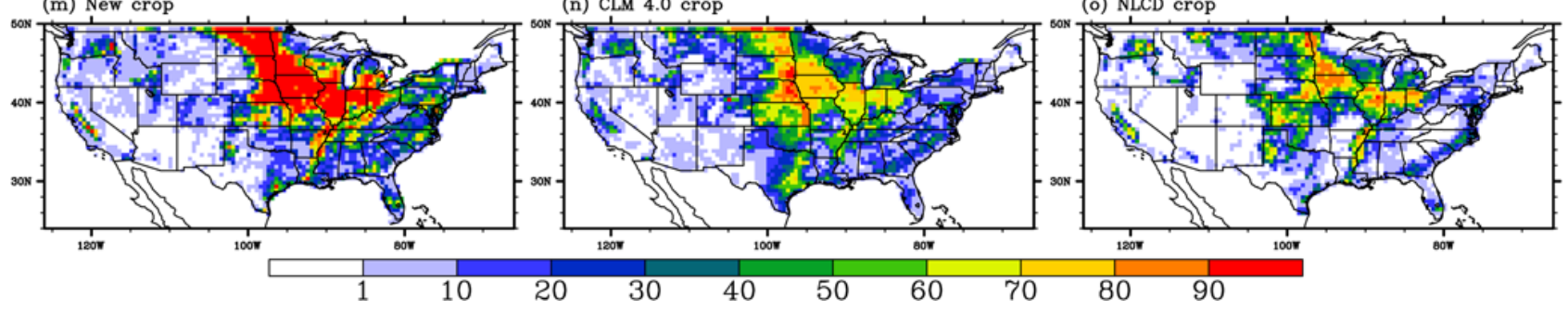

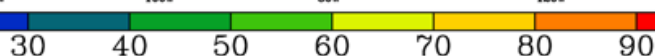

Fig. 4. Distribution of bare soil, shrub, grassland and crop over CONUS for new parameters, CLM 4.0 parameters and NLCD. (a) New bare soil; (b) CLM 4.0 bare soil; (c) NLCD bare soil; (d) New trees; (e) CLM 4.0 trees; (f) NLCD trees; (g) New shrub; (h) CLM 4.0 shrub; (i) NLCD shrub; (j) New grass; (k) CLM 4.0 grass; (l) NLCD grass; (m) New crop; (n) CLM 4.0 crop; (o) NLCD crop.

a larger coverage of crop in the new parameters, as shown in Fig. $4 \mathrm{~m}, \mathrm{n}$ and o. Over CONUS, both the new and CLM 4.0 parameters overestimate crop contribution compared to NLCD $(25.0 \%$ in new parameters and $20.5 \%$ in CLM parameters compared to $15.5 \%$ in NLCD). However, it is likely that NLCD underestimates crop coverage since the NASS survey shows a crop area of $20.3 \%$ in 2007 and $21.5 \%$ in 2002 over CONUS (Table 4).

\subsection{New LAI and SAI parameters}

Across all land, Table 5 shows that the new parameters have large decreases in combined LAI for all seasons, with the largest decrease in the months of JJA ( 0.93 compared to 1.09) and the smallest decrease in the months of DJF
(0.6 compared to 0.68 ). Figure 5 shows that the decreases are mainly distributed over the high latitude areas of the Northern Hemisphere, which is covered mostly by boreal needleleaf trees, and the eastern US that is covered by mixed trees, grass and crops in the new parameters and CLM 4.0 parameters. Regional analysis (Table 5) shows that the Northern Hemisphere boreal region has large decreases in LAI in all seasons, with the largest decrease in the summer (1.46 compared to 1.97) and smaller decrease in the other seasons $(0.52$ compared to 0.75 in winter, 1.1 compared to 1.34 in spring, and 0.61 compared to 0.83 in the autumn).

In contrast, the Amazon region has considerably higher LAI in all seasons in the new parameters (Fig. 5 and Table 5), with the largest increase during the summer season 

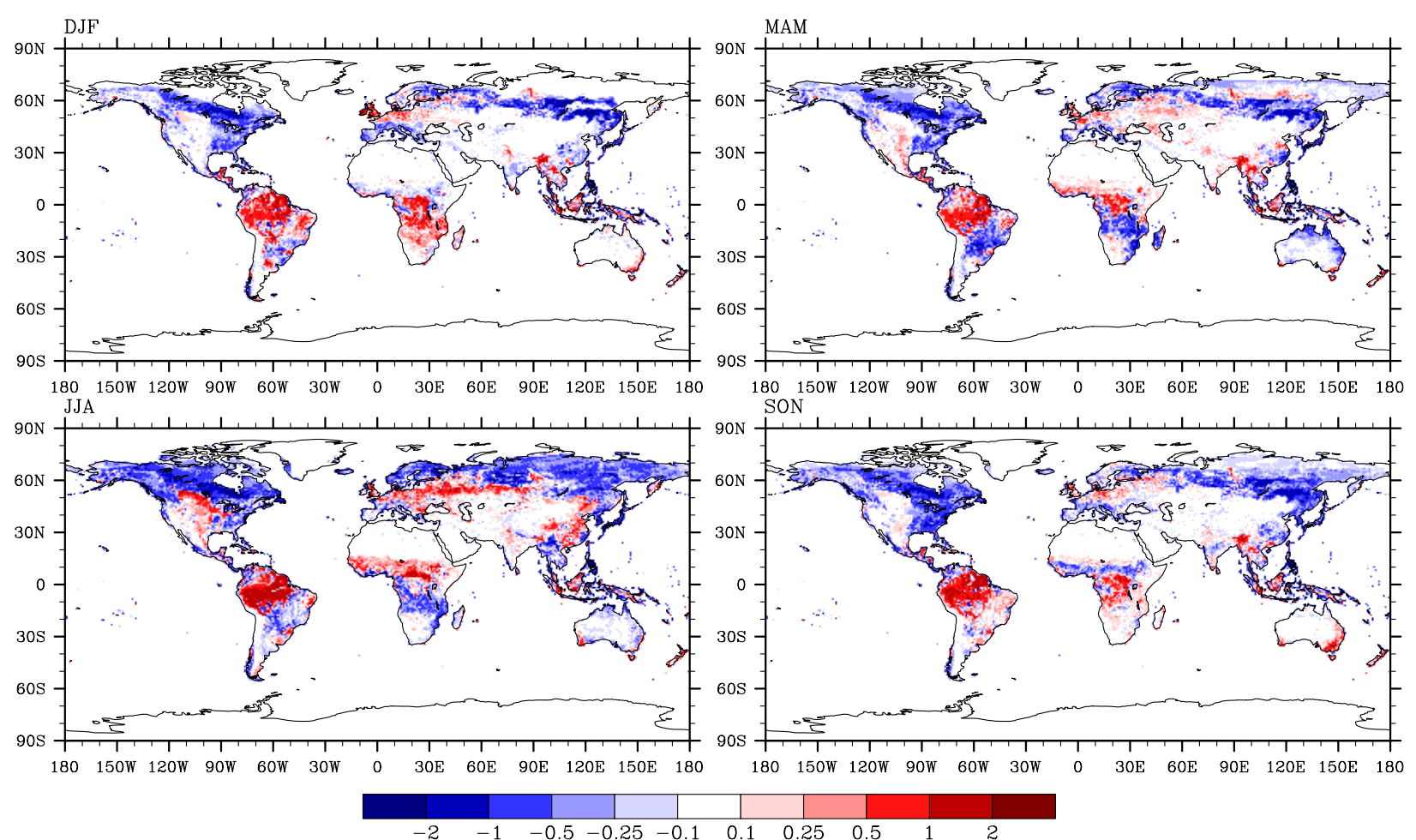

Fig. 5. Differences in seasonal LAI between new and CLM 4.0 parameters (new - CLM 4.0 LAI). Top-left: DJF; Top-right: MAM; Bottomleft: JJA; Bottom-right: SON.

Table 5. Average global and regional seasonal LAI and SAI for new and CLM 4.0 parameters.

\begin{tabular}{|c|c|c|c|c|c|c|c|c|}
\hline \multirow{2}{*}{ Season } & \multicolumn{2}{|c|}{ Global } & \multicolumn{2}{|c|}{ Boreal } & \multicolumn{2}{|c|}{ Amazon } & \multicolumn{2}{|c|}{ Sahara } \\
\hline & CLM 4.0 & New (Diff) & CLM 4.0 & New & CLM 4.0 & New & CLM 4.0 & New \\
\hline \multicolumn{9}{|l|}{ LAI } \\
\hline $\mathrm{DJF}$ & 0.68 & $0.60(-0.08)$ & 0.75 & $0.52(-0.23)$ & 3.02 & $3.33(+0.31)$ & 0.06 & $0.05(-0.01)$ \\
\hline MAM & 0.92 & $0.80(-0.12)$ & 1.34 & $1.10(-0.25)$ & 3.22 & $3.38(+0.16)$ & 0.05 & $0.06(+0.01)$ \\
\hline JJA & 1.09 & $0.93(-0.15)$ & 1.97 & $1.46(-0.51)$ & 3.09 & $3.49(+0.40)$ & 0.10 & $0.12(+0.02)$ \\
\hline SON & 0.73 & $0.63(-0.10)$ & 0.83 & $0.61(-0.22)$ & 2.99 & $3.27(+0.28)$ & 0.08 & $0.07(-0.01)$ \\
\hline \multicolumn{9}{|l|}{ SAI } \\
\hline DJF & 0.28 & $0.22(-0.06)$ & 0.52 & $0.40(-0.12)$ & 0.70 & $0.69(-0.01)$ & 0.03 & $0.03(+0.01)$ \\
\hline MAM & 0.29 & $0.24(-0.05)$ & 0.52 & $0.39(-0.13)$ & 0.70 & $0.72(+0.02)$ & 0.03 & $0.04(+0.01)$ \\
\hline JJA & 0.33 & $0.29(-0.04)$ & 0.71 & $0.64(-0.07)$ & 0.72 & $0.70(-0.02)$ & 0.03 & $0.04(+0.01)$ \\
\hline SON & 0.39 & $0.30(-0.09)$ & 0.80 & $0.55(-0.25)$ & 0.70 & $0.75(+0.05)$ & 0.05 & $0.06(+0.01)$ \\
\hline
\end{tabular}

(3.49 compared to 3.09) and the smallest increase in the spring season (3.38 compared to 3.22). The Central Africa and South Asia tropical forests also have a higher LAI during all seasons in the new parameters (Fig. 5). Sahara and Arabia regions have similar LAI during all seasons. In the southcentral region of Africa, where land cover is dominated by broadleaf deciduous trees, shrub and grass, the new parameters have increased LAI during austral spring and summer
(Fig. 5a and d), and decreased LAI during austral autumn and winter (Fig. 5b and c).

Evaluation of the new parameters against the MODIS improved LAI product (Fig. 6) shows that in the summer season, there are no observable differences in most land areas except for the slightly lower LAI in the eastern US and western Europe and higher LAI in coastal central Africa and Burma. In the months of MAM, SON, and DJF, the new parameters have distinctly higher LAI than the MODIS 

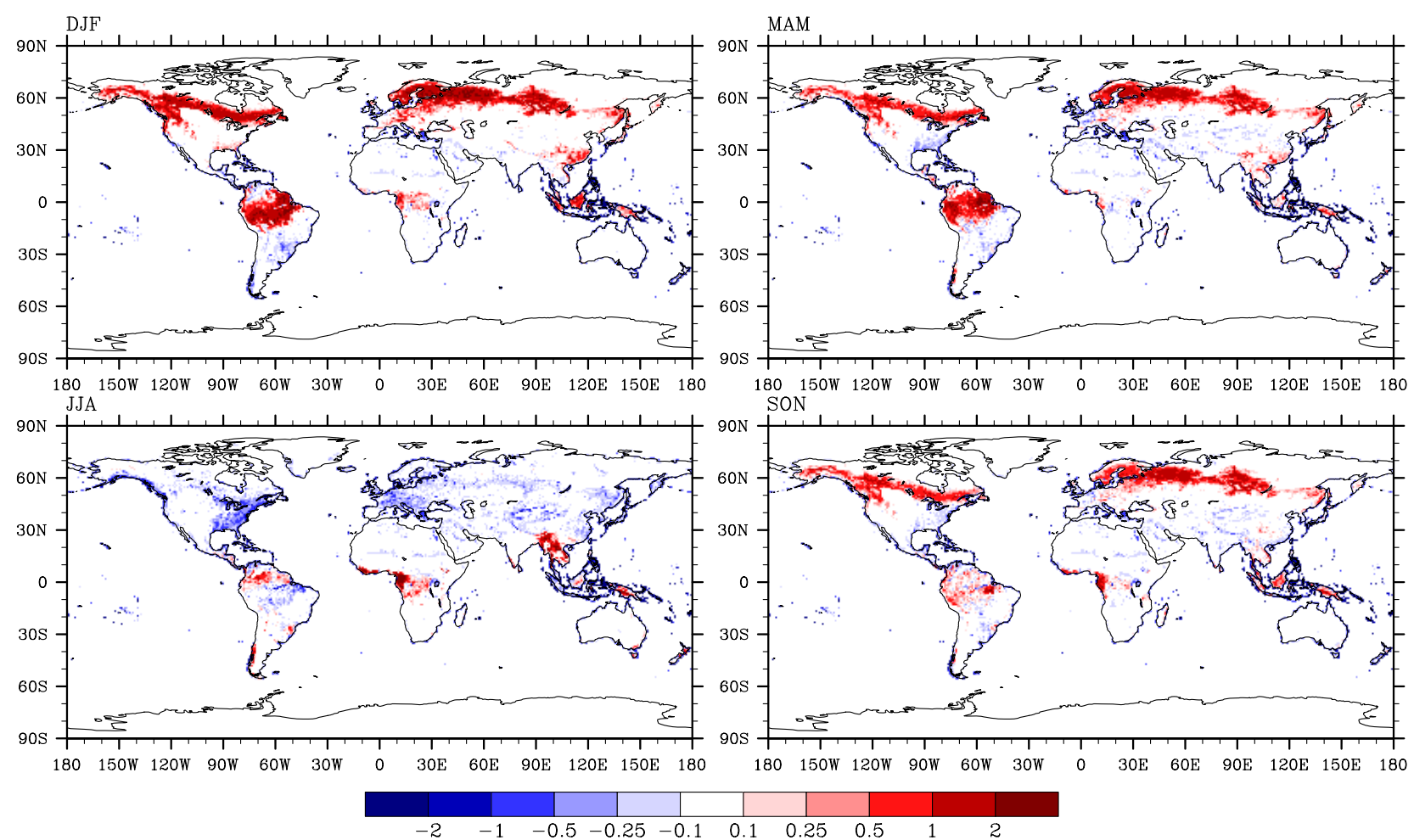

Fig. 6. Differences between new CLM LAI parameters and MODIS observed spatially and temporal improved LAI (new - MODIS LAI). Top-left: DJF; Top-right: MAM; Bottom-left: JJA; Bottom-right: SON.

improved LAI observations in the Amazon, Central Africa and Southeast Asia, which are covered by evergreen tropical forests, and the high latitude areas in the Northern Hemisphere, which includes Evergreen Boreal forest of northern North America, Europe and Russia.

Since SAI parameters are calculated from LAI following the same method in Chase and Lawrence (2007), it is not surprising that the new parameters have decreased SAI over all land during all seasons. Regional analysis shows that the boreal region has large decrease in SAI, with the largest decrease in boreal autumn ( 0.55 compared to 0.80$)$. The Amazon region has a small increase in the months MAM and SON for SAI, but decreased SAI for other seasons. The Sahara and Arabia region has increased SAI for all seasons. Spatial distribution of the differences shows a similar pattern with LAI differences (Fig. 7). Throughout the year, the new parameters have increased SAI over the Amazon tropical forests, but decreased SAI over high latitude Northern Hemisphere boreal forest, and eastern US. The African Savannah area has a slightly decreased DJF SAI, but slightly increased SON SAI.

\subsection{New PFT LAI Parameters in Northern and Southern Hemisphere}

The phenology cycles of each PFT LAI in the northern and Southern Hemisphere are shown in Figs. 8 and 9, respectively. Overall there are reasonable agreements between the two datasets, showing a larger phenology cycle for needleleaf and broadleaf deciduous boreal trees and broadleaf deciduous temperate trees compared to other PFTs. In addition, seasonal variations in phenology are generally larger in the Northern Hemisphere than Southern Hemisphere and distinct shifts in the seasonal timing are also noticeable in the PFTs, corresponding to the dominance of land mass in the subtropical/mid-latitude versus tropical regions and the change of season in the two hemispheres.

In the Northern Hemisphere, both the new and CLM 4.0 parameters have similar seasonal LAI values and phenology for needleleaf evergreen temperate trees (Fig. 8a). For needleleaf evergreen boreal trees, both parameter sets have similar LAI cycle in terms of the growing season start and end month, but the new parameters have considerably decreased LAI values compared to the CLM 4.0 parameters (1.9 compared to 2.1). For needleleaf deciduous boreal trees, the new parameters have similar LAI values as the current CLM 4.0 parameters, but with an earlier and more symmetrical growing season. 

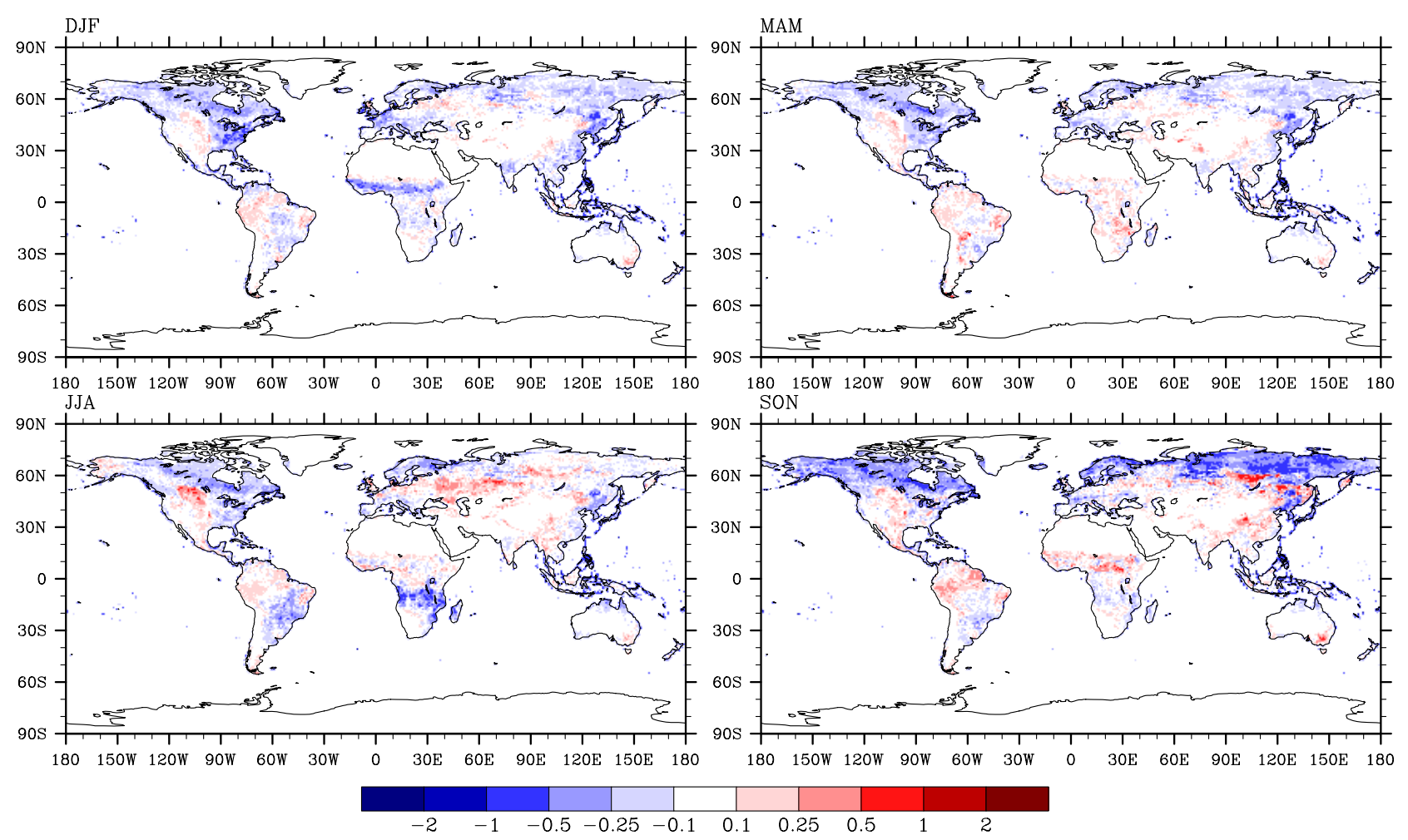

Fig. 7. Differences in seasonal SAI between new and CLM 4.0 parameters (new - CLM 4.0 LAI). Top-left: DJF; Top-right: MAM; Bottomleft: JJA; Bottom-right: SON.

Figure $8 \mathrm{~b}$ shows that the Broadleaf Evergreen Tropical trees have slightly lower average LAI in the new parameters (3.8 compared to 4.2), and the Broadleaf Evergreen Temperate trees have a substantially lower LAI in the new parameters (3.1 compared to 3.8). There is no distinct seasonality for both Broadleaf Evergreen Tropical and Temperate trees in both sets of parameters.

Figure $8 \mathrm{c}$ shows that both sets of parameters have generally similar seasonal cycles for Northern Hemisphere broadleaf deciduous trees. For Broadleaf Deciduous Tropical trees, the new parameters have slightly higher maximum LAI values (2.8 compared to 2.6) and slightly lower minimum LAI values (1.4 compared to 1.6). For Broadleaf Deciduous Temperate trees, the new parameters have a longer growing season and more distinct seasonal fluctuation, with noticeably higher maximum LAI values (3.1 compared to 2.7 ) and slightly lower minimum LAI values ( 0.9 compared to 1.1). Similarly, the Broadleaf Deciduous Boreal trees also have more distinct seasonal fluctuation in the new parameters, with a substantially higher maximum LAI value (3.8 compared to 2.9). In addition, the new parameters result in an earlier growing season and more symmetrical seasonal LAI phenology for the Broadleaf Deciduous Boreal trees.

Figure $8 \mathrm{~d}$ shows that the new parameters have similar LAI seasonal phenology and magnitude for Broadleaf Deciduous Temperate shrubs. For Broadleaf Evergreen Temperate shrub, the new parameters generate similar LAI phenology yet slightly lower LAI values (mean LAI of 0.7 compared to 0.9). For Broadleaf Deciduous Boreal shrub, the new parameters also have similar LAI phenology but substantially lower PFT LAI throughout the year (mean LAI of 0.4 compared to $0.9)$.

Figure 8e shows that the new parameters have similar LAI phenology cycles for the Northern Hemisphere grass PFTs. For $\mathrm{C} 4$ grass, the new parameters also have similar LAI values as the CLM 4.0 parameters. For both C3 Arctic and C3 non-Arctic grass, the new parameters generate substantially lower LAI throughout the year, with a mean LAI of 0.4 compared to 0.9 for $\mathrm{C} 3$ Arctic grass and 0.8 compared to 1.1 for $\mathrm{C} 3$ non-Arctic grass. For crops, Fig. $8 \mathrm{f}$ shows that the new parameters have generally similar phenology pattern but slightly greater seasonal fluctuation than CLM 4.0, with higher maximum LAI value (1.9 compared to 1.7 ) and lower minimum LAI value ( 0.6 compared to 0.8 ).

In the Southern Hemisphere, the new parameters have large differences in PFT LAI for Needleleaf trees (Fig. 9a). Both Needleleaf Evergreen Temperate trees and Needleleaf Evergreen Boreal trees have a substantially lower PFT LAI throughout the year in the new parameters, with a mean LAI value of 1.4 compared to 2.1 for the former PFT and mean LAI value of 0.9 compared to 2.4 for the latter. Neither PFT shows a significant phenology cycle in the new or CLM 4.0 

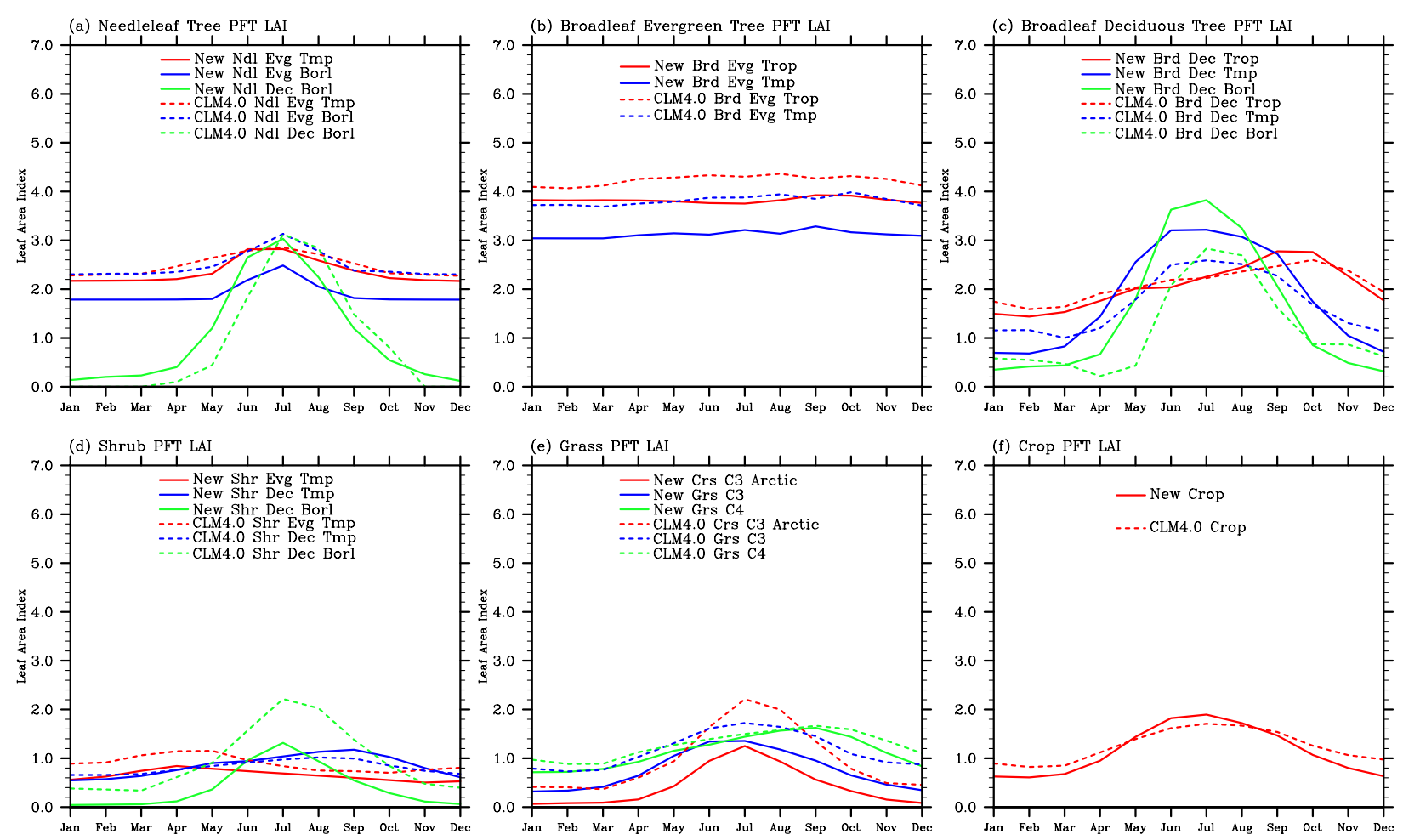

Fig. 8. Northern Hemisphere PFT LAI for new and CLM 4.0 parameters. The abbreviations of PFTs are same as in Table 3. (a) Needleleaf Tree PFT LAI; (b) Broadleaf Evergreen Tree PFT LAI; (c) Broadleaf Deciduous Tree PFT LAI; (d) Shrub PFT LAI; (e) Grass PFT LAI; (f) Crop PFT LAI.

parameters. No Needleleaf Deciduous Boreal trees are found in the Southern Hemisphere for the CLM 4.0 parameters, but the new parameters report a sparse coverage of Needleleaf Deciduous Boreal trees, with $4 \%$ distributed in the Southern Hemisphere and $96 \%$ distributed in the Northern Hemisphere. The Southern Hemisphere Needleleaf Deciduous Boreal trees have an average LAI of 1.0.

For Broadleaf Evergreen, Fig. 9b shows that the new and CLM 4.0 parameters have good agreement. For Broadleaf Deciduous, Fig. 9c shows that the new parameters have a significantly different PFT LAI phenology cycle for the Southern Hemisphere, with the maximum LAI occurring about two months earlier and with larger seasonal fluctuations than the CLM 4.0 parameters. Figure 9d shows that the new parameters generally have a lower LAI for Southern Hemisphere shrubs. For Broadleaf Evergreen Temperate shrubs, the new parameters also have a different phenology pattern, with the maximum LAI value in austral summer compared to September and October.

Figure 9e shows that the new parameters have lower PFT LAI values for Southern Hemisphere grasses. For C3 Arctic grass, the new parameters produced a similar phenology cycle, yet lower LAI values than the current CLM 4.0 parameters throughout the year, with average LAI values of $0.6 \mathrm{com}$ pared to 0.9 in CLM 4.0 parameters. For C3 non-Arctic grass, the new parameters show the LAI phenology cycle begins two months earlier, with maximum LAI in February compared to April, and slightly lower maximum LAI values (1.4 compared to 1.6). Similarly, for $\mathrm{C} 4$ grass, the new parameters also had an earlier (February compared to April) and slightly lower maximum LAI (1.6 compared to 1.8). Figure 9f shows that the new parameters have different LAI phenology for the Southern Hemisphere crops, with the new parameters peaking two months earlier than the CLM 4.0 parameters (February compared to April) with smaller seasonal fluctuation.

\subsection{Non-vegetated parameters}

Over all land, the new parameters have significantly increased coverage of lake compared to the current CLM 4.0 parameters $(1.4 \%$ compared to $0.52 \%)$. Figure $10 \mathrm{a}$ and $\mathrm{b}$ show that the large increases are mainly distributed in the regions of Canadian Shield, Scandinavia, Siberia, and Tibet plateau. The contribution from wetland also has distinct increase in the new parameters $(1.0 \%$ compared to $0.25 \%)$. Likewise, the wetland areas represented in the new parameters are mainly distributed in Canadian Shield, Scandinavia, west Siberia regions, and South America and Central Africa also have increased contribution from wetland (Fig. 10c and d). 

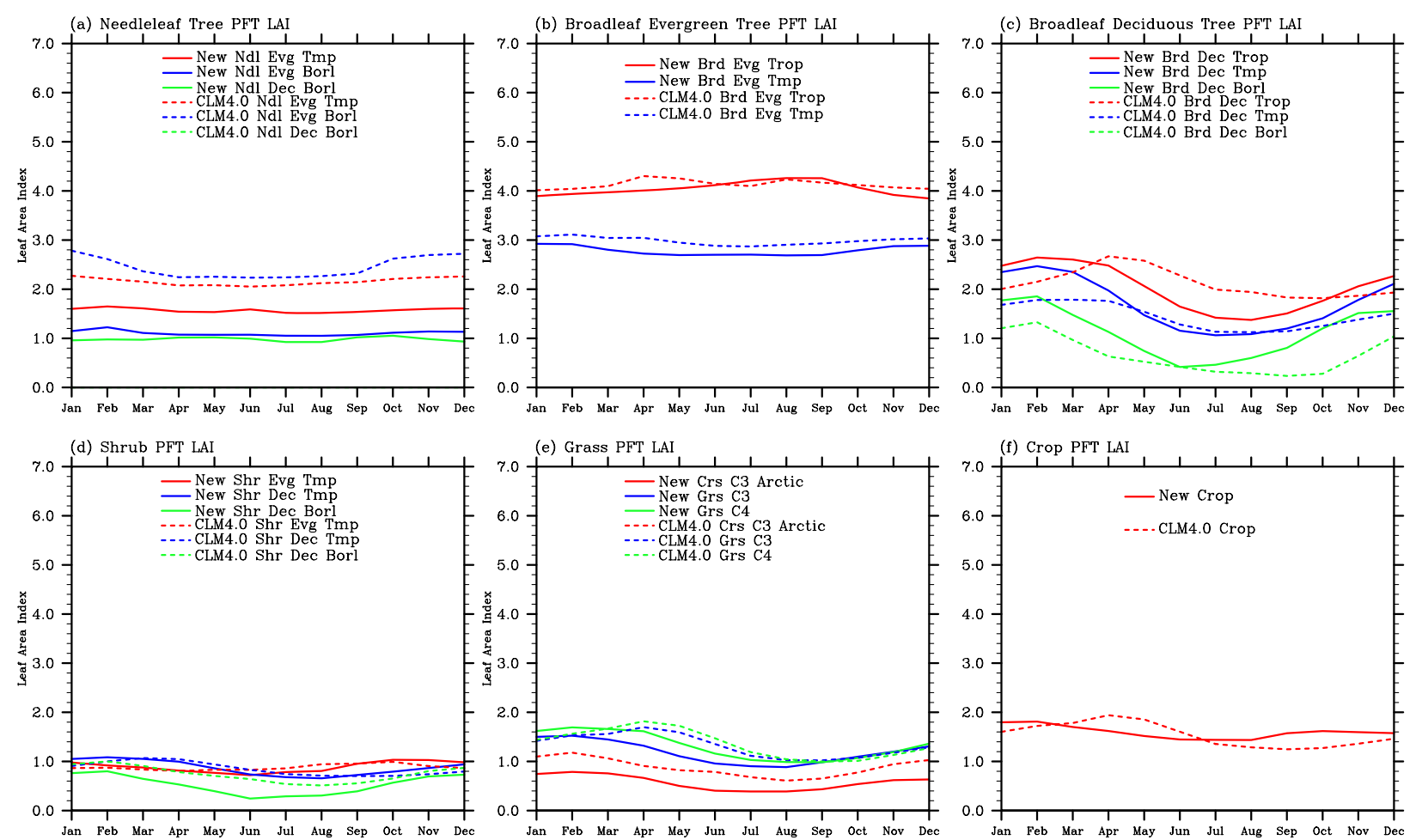

Fig. 9. Southern Hemisphere PFT LAI for new and CLM 4.0 parameters. The abbreviations of PFTs are same as in Table 3. (a) Needleleaf Tree PFT LAI; (b) Broadleaf Evergreen Tree PFT LAI; (c) Broadleaf Deciduous Tree PFT LAI; (d) Shrub PFT LAI; (e) Grass PFT LAI; (f) Crop PFT LAI.

The new parameters reduce urban area $(0.44 \%$ compared to $0.64 \%$ ) over all land, and Fig. 10e and f show significant decrease over India and eastern China. There is a slight increase in urban area over the US and southeast Brazil. Glacier increases slightly in the new parameters over the tundra area of Canada and Russia, and the Tibet plateau.

\subsection{Surface climate over western US}

A one-year simulation is not long enough to allow CLM to be spun up to simulate realistic land surface conditions for the simulation period. Nevertheless, to demonstrate how highresolution surface parameters could be used to support regional climate modeling, simulated surface albedo and surface fluxes are plotted to provide some indications of the impacts of grid resolution in simulating land-atmosphere interactions. Figure 11 shows the simulated surface albedo and sensible and latent heat fluxes for the summer (June-JulyAugust) after eight months of simulation. Spatial variability of surface albedo shows important features arising from mountain snowpack over the Central and Northern Rocky Mountain and at the higher latitudes. Surface albedo is generally rather uniform elsewhere, but lower albedo values corresponding to the forest along the Coastal Range, Cascades, and Sierra Nevada of Washington and California are clearly shown, as well as higher albedo values corresponding to the bare soil seen in the high resolution data displayed in Fig. 4a. Sensible and latent heat fluxes are dominated by spatial variability associated with topography and mountain snowpack. Nevertheless, some spatial variability can be identified that corresponds with fine spatial features of vegetation that influence sensible and latent heat fluxes, e.g. lower Bowen ratio at North Dakota, South Dakota, Nebraska, Kansas, Oklahoma where grass dominates (Fig. 11d). However, we also noted some jagged patterns in the latent heat flux (e.g. in western Montana) due to the coarse resolution soil texture data used in the simulation. This shows the sensitivity of surface heat fluxes to different surface parameters and highlights the importance of developing a consistent high-resolution dataset for all the vegetation and soil parameters for high-resolution land surface modeling.

\section{Discussion}

A new set of high-resolution $\left(0.05^{\circ}\right)$ CLM land surface parameters has been generated consistently from the latest version of MODIS land cover product (MCD12Q1 C5) and an improved MODIS LAI product in the year 2005. Our analysis shows that the new parameters could resolve more PFTs within each $0.5^{\circ}$-grid compared to the current CLM 4.0 land parameters. The comparison between the new and the 

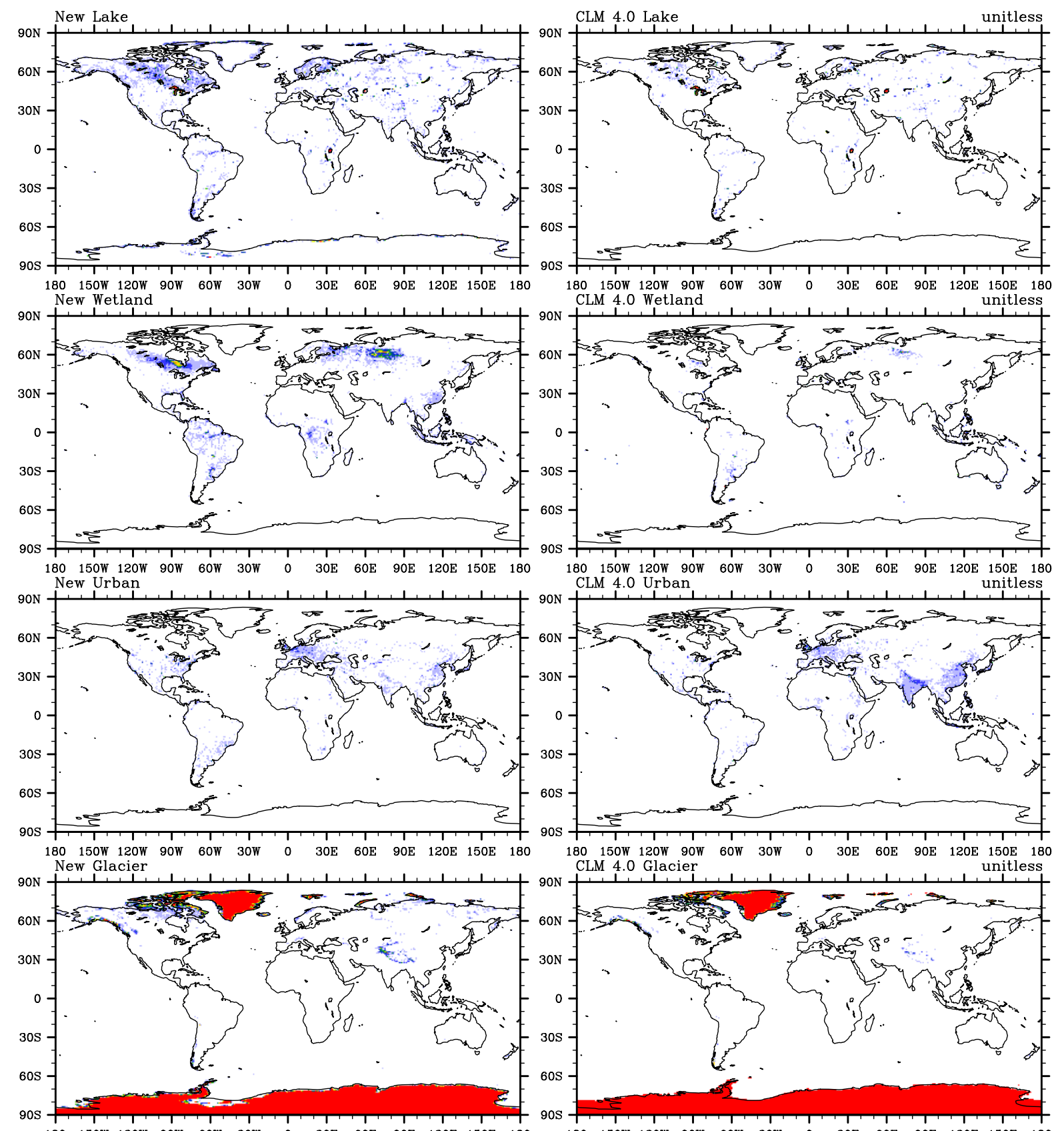

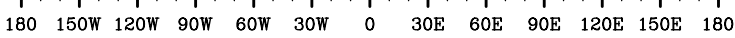

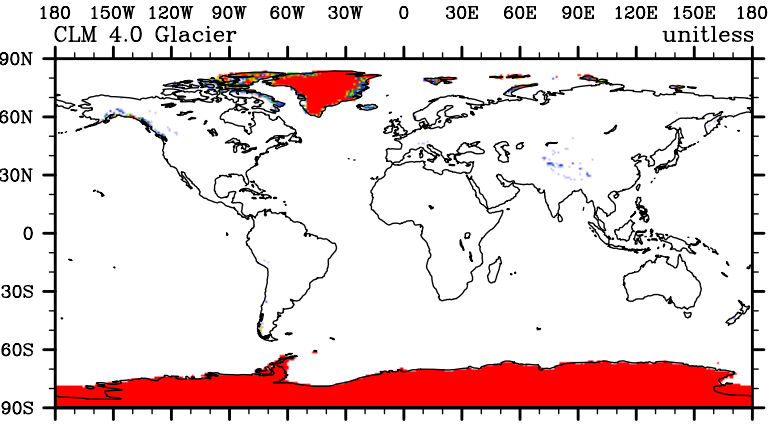

$1 \quad 10 \quad 20 \quad 30 \quad 40 \quad 50 \quad 60 \quad 70 \quad 8090$

Fig. 10. Global distribution of non-vegetated land cover for new and CLM 4.0 parameters. Left panel from top to bottom: New Lake; New Wetland; New Urban; New Glacier. Right panel from top to bottom: CLM 4.0 Lake; CLM 4.0 Wetland; CLM 4.0 Urban; CLM 4.0 Glacier.

current CLM 4.0 land surface parameters shows large differences in the global distribution of PFTs. Overall, in the new parameters the global land have decreased contribution from bare soil and tree PFTs, but increased contribution from shrub, grass and crop, with the largest decrease in bare soil and increase in shrub land. This pattern is also found over CONUS. Although it is difficult to assess accuracies of both parameters globally due to limited availability of global ground-truth data, we attempted to use higher-resolution NLCD to evaluate both datasets. The evaluation shows that the shrub lands and bare soil estimated by the new parameters are more comparable to NLCD. However, this could be partly due to the different land cover representations used in the land cover classification product and vegetation continuous 

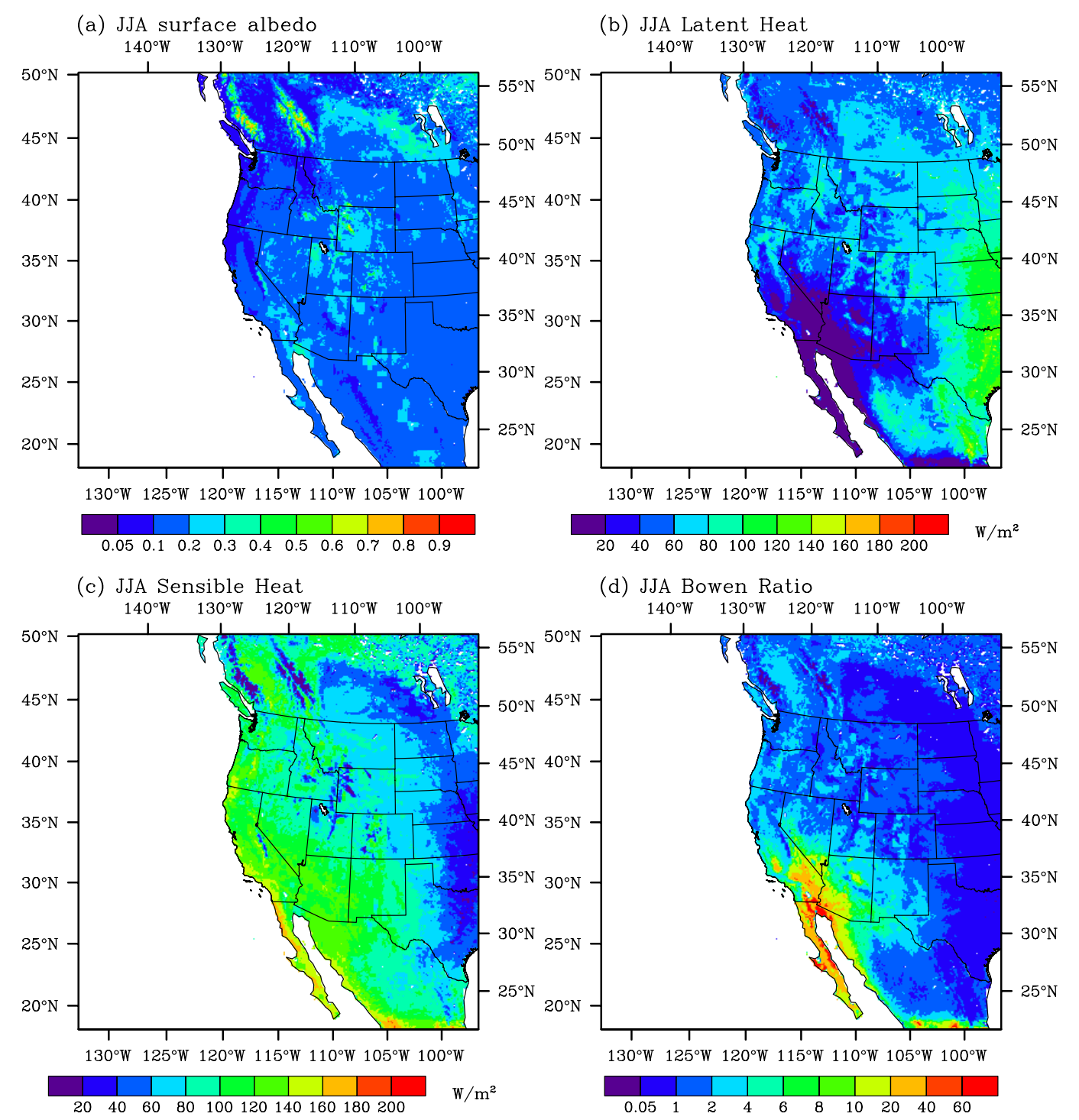

Fig. 11. Model simulated surface variables over western US using new parameters. (a) Surface temperature. (b) Sensible heat. (c) Latent heat. (d) Bowen ratio.

field product. Both MCD12Q1 and NLCD data classified pixels (500 $\mathrm{m}$ in MCD12Q1 and $30 \mathrm{~m}$ in NLCD) into dominant land cover types (e.g. NLCD defined "barren land" as area that has at least $85 \%$ non-vegetated coverage), while MODIS VCF estimated the composition of bare soil, trees, and herbaceous within each pixel.

Differences between the new and the current CLM 4.0 land surface parameters mainly came from the different data sources and methods used for developing the datasets. Both methods have advantages and disadvantages. In the MODIS VCF product and AVHRR Continuous Field Tree Cover product used to generate the current CLM 4.0, global land is represented as vegetated and/or non-vegetated land fraction within each $500 \mathrm{~m}$ grid. This representation is consistent with the concept of ecosystem composition and structure in CLM, where each model grid is defined as patches of PFTs (Bonan et al., 2002a). Compared to the discrete classification-based land representation in products such as MCD12Q1 used in our method, this representation is superior in regions dominated by less homogeneous landscape (e.g. the shrub land in Australia). Once validated, such products are ideal for deriving PFT composition in CLM.

Unfortunately, none of the vegetation fraction products that currently exist has been fully evaluated or validated. Besides the two data products used to develop the current CLM 4.0 parameters, the newer version of MODIS VCF (Collection 4) was developed for the year of 2005 and contains fractional tree cover data only. Among the three 
Table 6. Average global non-vegetated land cover composition.

\begin{tabular}{lrrr}
\hline Land Cover & CLM 4.0 & New & Diff \\
\hline Lake & 0.52 & 1.4 & 0.88 \\
Wetland & 0.25 & 1.0 & 0.75 \\
Urban & 0.64 & 0.44 & -0.2 \\
Glacier & 10.4 & 10.6 & 0.2 \\
\hline
\end{tabular}

datasets, only MODIS VCF Collection 3 that was used to generate the current CLM 4.0 parameters provides overall vegetation (tree + herbaceous) and non-vegetated fraction. However, existing validations of the MODIS VCF Collection 3 tree cover data reported various qualities across biomes (Hansen et al., 2003; Montesano et al., 2009; White et al., 2005; Jeganathan et al., 2009) and no studies have yet been performed to validate the bare soil/herbaceous coverage. Using products that have not been systematically validated may introduce great uncertainties in defining PFTs. For example, the CLM4 bare ground coverage derived from the MODIS VCF Collection 3 bare soil percentage is much higher than that estimated by Poulter et al. (2011), Bonan et al. (2002a), and Jung et al. (2007). Our evaluation over CONUS shows that the MODIS VCF has considerable overestimation of bare soil, even if only land with over $85 \%$ of bare soil is considered (3.5\% compared to $2.0 \%$ in Table 3 ). In contrast, the bare ground coverage derived using our method is much closer to the above studies and the NLCD bare ground fraction over the US. Therefore, it is very likely that the MODIS VCF product generally overestimates bare ground percentage. Similarly, White et al. (2005) reported that VCF underestimates tree cover, i.e. overestimates bare ground in southwestern US, which is consistent with our findings using NLCD (Fig. 4a-c). Montesano et al. (2009) also pointed out that the MODIS VCF data may not be sufficient for monitoring tree cover in the taiga-tundra transition zone.

Using bare ground fraction that was not validated can introduce uncertainty not only through uncertainty of the bare ground data itself, but the MODIS LAI, which represents the averaged LAI over a pixel, must be modified to eliminate the influence of bare ground to be consistent with the PFT derived with vegetation fraction data. This would further introduce uncertainty because assumptions are needed to estimate PFT LAI from the averaged LAI over a pixel. The combined use of MODIS VCF and other land cover data that correspond to conditions for different years (e.g. AVHRR Continuous Fields Tree Cover Project data in 1992-1993) adds further uncertainty because land conditions have dramatically changed in some regions during the ten years period. Mixing data from different years also hinders the development of land cover time series consistent with the satellite records for land cover change simulations (Bontemps et al., 2012). Lastly, validating the resulting PFT LAI globally will present significant challenges to support its use in land surface modeling.
In contrast, the MODIS land cover product MCD12Q1 C5 used in our method has been evaluated systematically and demonstrated to have an overall accuracy of over $75 \%$ (Friedl et al., 2010), meaning that on average $75 \%$ of the land area was correctly classified. The accuracy of each land cover class can also be used to provide guidance of the PFT accuracy. For example, cropland was reported to have low to moderate accuracies in the MODIS land cover product (Friedl et al., 2010). This is consistent with our findings. Our evaluation over CONUS shows that the new parameters have significant overestimation of cropland compared to the USDA NASS statistics. The overestimation is mainly distributed over Midwest US, where both CLM 4.0 and NLCD show considerable percentage of grass, indicating that MCD12Q1 might have poor performance in distinguishing crop from grass.

Although without vegetation fractional information, land cover classification products such as MCD12Q1 have been extensively used to develop PFT parameters in a way similar to our method (Bonan et al., 2002a; Jung et al., 2006, 2007; Poulter et al., 2011). For example, Bonan et al. (2002a) used the AVHRR $1 \mathrm{~km}$ IGBP DISCover land cover data set to determine non-tree-covered PFT composition, and the bare ground composition was derived using exactly the same approach as our method. Besides, the method we adopted derives PFT and its LAI from MODIS data defined over each $500 \mathrm{~m}$ pixel, with the added advantage of using land cover and LAI from the same year for consistency. The spatial and temporal consistency between PFT and LAI is important not only because erroneous LAI information can have important negative effects, as LAI is used in many calculations in CLM, but also because it enables the development of high-resolution PFT LAI parameter. Using MODIS land cover and LAI products in a particular year to represent current land condition also facilitates the development of a MODIS-consistent transient land cover dataset for use with high-resolution CLM applications in the future.

Despite the above advantages, our approach has obvious limitations. As mentioned, the underlying assumption of our method is that each $500 \mathrm{~m}$ pixel in the MODIS land cover product was exclusively covered by one land cover type. This assumption is valid in most areas since a $500 \mathrm{~m} \times 500 \mathrm{~m}$ grid may be small enough to be covered by homogeneous landscape. However, this assumption will cause distortion in less homogeneous landscape such as shrub land, which explains the big differences in shrub and bare ground coverage between the new and CLM4 datasets. For example, the new parameters report over $90 \%$ of shrub coverage at central Australia while the current CLM 4.0 parameters have a mixture of bare soil, shrub and grass coverage, which is more realistic in that area. This issue can be less significant if land cover product can represent inhomogeneous areas at higher spatial resolution or use more detailed land cover categories (Poulter et al., 2011). Future version of MODIS land cover data (MCD12Q1 C6) is proposed to migrate to 
the LCCS-compliant classification scheme that has a larger number of legend categories and produces higher accuracy of land cover (MODIS Land Science Collection 6 Test, NASA). These improvements will greatly benefit the representation of land surface using MODIS land cover product in the future. Potential improvement can also be made by estimating fraction of PFTs within each MCD12Q1 grid cell based on both dominant classes provided by MCD12Q1 and supporting remotely sensed data such as vegetation indices or vegetation vertical structure from Light Detection and Ranging (LiDAR) data.

The new parameters have an overall decrease of combined LAI for all seasons and a large discrepancy in spatial distribution of combined LAI compared to the CLM 4.0 parameters, especially in tropical and boreal regions. In tropical region, the new parameters produce substantially higher LAI values for all seasons, while in high latitude Northern Hemisphere the new parameters have substantially lower LAI values. This reflects the large change made in the improved LAI product compared to the original MODIS LAI product (MOD15A2 C4) used by CLM 4.0 parameters. First, the improved LAI product is based on the latest release of MODIS LAI (MOD15A2 C5) rather than MOD15A2 C4, which has overestimation in global LAI reported by many studies (Fang et al., 2012; Fang and Liang, 2005; Garrigues, 2008; Hill et al., 2006; Pisek and Chen, 2007; Weiss et al., 2007). Second, the PFT LAI in CLM 4.0 parameters is calculated from the three-year monthly mean LAI. Yuan et al. (2011) pointed out that the multi-year mean monthly LAI tend to underestimate the real LAI value in the tropical region because of the large fluctuation of LAI time-series due to frequent cloud cover. The improved LAI product used the latest release of MODIS LAI (MOD15A2 C5) that adopted temporal spatial filter to avoid this problem and yielded more accurate LAI estimation validated using observation data. However, MOD15A2 C5 was reported to have underestimation of needleleaf LAI (De Kauwe et al. 2011), which explained that the new parameters have decreased combined LAI in the Northern Hemisphere boreal region. Since the combined LAI analysis is also influenced by the PFT fraction, the increased broadleaf trees in the tropical forest and decreased Needleleaf trees in the boreal region also contributed to the higher combined LAI in tropical and lower LAI in boreal region.

The new parameters have generally good agreement with MODIS JJA LAI globally except for some temperate and tropical regions. The differences can be attributed to the adjustment of maximum and minimum PFT LAI based on the method in Bonan et al. (2002a). Likewise, the increase of tropical and boreal LAI in tropical and boreal region during DJF, MAM, and SON seasons may also have resulted from the adjustment for Evergreen trees LAI, which confines the lower limit of LAI to be the fraction of maximum monthly LAI. This also indicates that MODIS LAI data need to be improved in the higher latitude area to alleviate the underestimation of LAI caused by snow contamination in cold seasons.

The new parameters adopt the same method of SAI mapping as Lawrence and Chase (2007), which was based on the combination of PFT LAI and SAI phenology. Thus the differences between SAI in the new parameters and SAI in the CLM 4.0 parameters have similar spatial distribution as LAI differences.

The individual PFT LAI analysis shows the differences between the new parameters and CLM 4.0 parameters in terms of the LAI phenology cycle for each PFT. Overall, the new parameters have similar or lower average LAI for all PFTs in both northern and Southern Hemisphere except the Broadleaf Evergreen trees in Southern Hemisphere and Broadleaf Deciduous trees in both Northern and Southern Hemisphere. In addition, the Broadleaf Deciduous Temperate and Boreal trees have greater LAI phenology fluctuation with higher maximum LAI and lower minimum LAI. In the Southern Hemisphere, the new parameters have better representation of phenology cycle, with LAI reaching maximum in austral summer and minimum in austral winter.

The new non-vegetated land cover parameters at $0.05^{\circ}$ resolution were aggregated to $0.5^{\circ}$ for comparison with the CLM 4.0 parameters. The new parameters produced slightly increased glacier coverage and substantially increased lake and wetland coverage. It is believed that the lake coverage estimated by the new parameters is more realistic since MCD12Q1 $500 \mathrm{~m}$ product has over $95 \%$ of accuracy in open water identification (Friedl et al., 2010) while the CLM 4.0 lake percentage is based on outdated freshwater map at resolution of $1^{\circ}$. There is a considerable decrease in urban area in the new parameters. This can be explained by the fact that the new urban parameter is based on MCD12Q1, which identifies buildings and man-made structures as urban area while the CLM 4.0 parameters used LandScan population data to estimate urban area.

The simulation of WRF-CLM using the new land surface parameters over western US showed finer scale features on top of the dominant topographic patterns corresponding to the high-resolution surface parameters. To support the simulation, we developed a method to remap the CLM input data defined on regular latitude-longitude geographic coordinate system onto the fixed-distance WRF grids generated with map projection, such as the Lambert Conformal projection. This remapping method is useful for coupling CLM with mesoscale models that commonly use map projections for grid generation. The experiment highlighted spatially resolved features that are enabled by using the higher resolution CLM input data, such as the one developed in this study. Since higher resolution or improved land surface datasets do not necessarily improve land surface modeling in coupled simulations, more analyses will be needed to understand the differences in coupled simulations using the CLM 4.0 and the new dataset in the future. The global high-resolution parameters can be used in high-resolution offline and coupled 
modeling globally to support different scientific investigations or development of high-resolution data assimilation products.

\section{Conclusions}

In this study we developed high-resolution global land surface data for the Community Land Model that enables the model to simulate detailed land surface processes at regional scale. Compared to the current CLM 4.0 parameters, the new land surface parameters not only have much higher resolution but they are also generated consistently from the latest MODIS land cover MCD12Q1 C5 and improved MODIS LAI product which have been systematically validated.

Our analysis shows that the new parameters generally identify more PFTs per grid than the current CLM 4.0 parameters due to the higher spatial resolution of MODIS land cover products. Over global land, the new parameters have decreased contribution from bare soil and trees, but increased contribution from grass, shrub and crop. The differences stem from the change in the data sources and the methods used for developing the new and the current CLM 4.0 PFT parameters. The comparison of the new and the current CLM 4.0 parameters shows that both methods have limitations because different assumptions have to be used and uncertainties are introduced owing to limitations in the global land products available. Rather than suggesting that one dataset is more accurate than the other, which is not possible to establish given the challenges in validating these datasets, this study aims to document the method adopted to develop the new data and compare the method and data with the current CLM4 parameters to provide guidance on their use for land surface modeling. Improvements in future remotely sensed land product will greatly enhance land surface representations in CLM land parameters.

Compared to the current CLM 4.0 parameters, the new parameters have increased LAI and SAI in tropical region while decreased LAI and SAI in boreal region. The combined LAI in the new parameters are close to the improved MODIS LAI in JJA, while higher than the observed LAI in the Northern Hemisphere boreal region during other seasons due to the adjustment for evergreen trees. This suggests that MODIS may be improved in the cold season to alleviate snow contamination.

The new parameters provide higher resolution nonvegetated land cover, and more realistic land water representation. Our regional climate simulation based on the new parameters over Western US show that the finer scale land surface datasets improve the resolution of model surface heat fluxes, which highlights the importance of developing highresolution datasets for land surface modeling. Future work will include global tests of CLM in order to examine the impact of the land parameter change on simulated land surface processes.
Acknowledgements. Development of the high-resolution surface parameters and the WRF-CLM coupled simulation was supported by the Pacific Northwest National Laboratory (PNNL) Integrated Regional Earth System Modeling (iRESM) Initiative. Analysis and evaluation of the high-resolution surface parameters were supported as part of the efforts to develop a new subgrid classification scheme for CLM for the Climate Science for Sustainable Energy Future (CSSEF) Project funded by the Department of Energy Earth System Modeling Program. PNNL is operated by Battelle for the DOE under Contract DE-AC06-76RLO 1830.

Edited by: D. Lawrence

\section{References}

Bonan, G. B., Levis, S., Kergoat, L., and Oleson, K. W.: Landscapes as patches of plant functional types: An integrating concept for climate and ecosystem models, Global Biogeochem. Cy., 16, 51-5-25, doi:10.1029/2000GB001360, 2002a.

Bonan, G. B., Oleson, K. W., Vertenstein, M., Levis, S., Zeng, X., Dai, Y., Dickinson, R. E., and Yang, Z. L.: The land surface climatology of the Community Land Model coupled to the NCAR Community Climate Model, J. Climate, 15, 3123-3149, 2002b.

Bontemps, S., Herold, M., Kooistra, L., van Groenestijn, A., Hartley, A., Arino, O., Moreau, I., and Defourny, P.: Revisiting land cover observation to address the needs of the climate modeling community, Biogeosciences, 9, 2145-2157, doi:10.5194/bg9-2145-2012, 2012.

Cogley, J. G.: GGHYDRO - Global Hydrographic Data Release 2.0. Trent Climate Note 91-1, Dept. Geography, Trent University, Peterborough, Ontario, 1991.

De Kauwe, M. G., Disney, M. I., Quaif, T., Lewis, P., and Williams, M.: An assessment of the MODIS collection 5 leaf area index product for a region of mixed coniferous forest, Remote Sens. Environ., 115, 767-780, 2011.

Dickinson, R. E., Oleson, K. W., Bonan, G., Hoffman, F., Thornton, P., Vertenstein, M., Yang, Z. L., and Zeng, X.: The Community Land Model and its climate statistics as a component of the Community Climate System Model, J. Climate, 19, 2302-2324, 2006.

Fang, H. and Liang, S.: A hybrid inversion method for mapping leaf area index from MODIS data: Experiments and application to broadleaf and needleleaf canopies, Remote Sens. Environ., 94, 405-424, 2005.

Fang, H., Wei, S., and Liang, S.: Validation of MODIS and CYCLOPES LAI products using global field measurement data, Remote Sens. Environ., 119, 43-54, 2012.

Friedl, M. A., Sulla-Menashe, D., Tan, B., Schneider, A., Ramankutty, N., Sibley, A., and Huang, X.: MODIS Collection 5 Global Land Cover: Algorithm refinements and characterization of new datasets, Remote Sens. Environ., 114, 168-182, 2010.

Fry, J., Xian, G., Jin, S., Dewitz, J., Homer, C., Yang, L., Barnes, C., Herold, N., and Wickham, J.: Completion of the $2006 \mathrm{Na}-$ tional Land Cover Database for the Conterminous United States, Photogramm. Eng. Remote Sens., 77, 858-864, 2011.

Garrigues, S., Lacaze, R., Baret, F., Morisette J. T., Weiss, M., Nickeson, J. E., Fernandes, R., Plummer, S., Shabanov, N. V., Myneni, R. B., Knyazikhin, Y., and Yang, W.: Validation and intercomparison of global Leaf Area Index products de- 
rived from remote sensing data, J. Geophys. Res., 113, G02028, doi:10.1029/2007JG000635, 2008.

Hansen, M. C., DeFries, R. S., Townshend, J. R. G., Carroll, M., Dimiceli, C., and Sohlberg, R. A.: Global Percent Tree Cover at a Spatial Resolution of 500 Meters: First Results of the MODIS Vegetation Continuous Fields Algorithm, Earth Interact., 7, 1$15,2003$.

Hijmans, R. J., Cameron, S. E., Parra, J. L., Jones, P. G., and Jarvis, A.: Very high resolution interpolated climate surfaces for global land areas, Int. J. Climatol., 25, 1965-1978, 2005.

Hill, M. J., Senarath, U., Lee, A., Zeppel, M., Nightingale, J. M., Williams, R. D. J., and McVicar, T. R.: Assessment of the MODIS LAI product for Australian ecosystems. Remote Sens. Environ., 101, 495-518, 2006.

Jeganathan, C., Dadhwal, V. K., Gupta, K., and Raju, P. L. N.: Comparison of MODIS vegetation continuous field - based forest density maps with IRS-LISS III derived maps, J. Indian Soc. Remote Sens., 37, 539-549, 2009.

Jin, J., Miller, N. L., and Schlegel, N.: Sensitivity Study of Four Land Surface Schemes in the WRF Model, Adv. Meteorol., 2010, 167436, doi:10.1155/2010/167436, 2010.

Jung, M., Henkel, K., Herold, M., and Churkina, G.: Exploiting synergies of global land cover products for carbon cycle modeling, Remote Sens. Environ., 101, 534-553, 2006.

Jung, M., Vetter, M., Herold, M., Churkina, G., Reichstern, M., Zaehle, S., Ciais, P., Viovy, N., Bondeau, A., Chen, Y., Trusilova, K., Feser, F., and Heimann, M.: Uncertainties of modeling gross primary productivity over Europe: A systematic study on the effects of using different drivers and terrestrial biosphere models, Global Biogeochem. Cy., 21, GB4021, doi:10.1029/2006GB002915, 2007.

Lawrence, P. J. and Chase, T. N.: Representing a MODIS consistent land surface in the Community Land Model (CLM 3.0): Part 1. Generating MODIS consistent land surface parameters, Coop. Inst. for Res. in Environ. Sci., Univ. of Colo., Boulder, 2006.

Lawrence, P. J. and Chase, T. N.: Representing a new MODIS consistent land surface in the Community Land Model (CLM 3.0), J. Geophys. Res., 112, G01023, doi:10.1029/2006JG000168, 2007.

Lawrence, D., Oleson, K. W., Flanner, M. G., Thorton, P. E., Swenson, S. C., Lawrence, P. J., Zeng, X., Yang, Z. L., Levis, S., and Skaguchi, K.: Parameterization improvements and functional and structural advances in version 4 of the Community Land Model, J. Adv. Model. Earth Syst., 3, M03001, doi:10.1029/2011MS000045, 2011.

Leung, L. R., Kuo, Y.-H., and Tribbia, J.: Research Needs and Directions of Regional Climate Modeling Using WRF and CCSM, B. Am. Meteorol. Soc., 87, 1747-1751, doi:10.1175/BAMS-8712-1747, 2006.

Li, H., Huang, M., Wigmosta, M. S., Ke, Y., Coleman, A. M., Leung, L. R., Wang, A., and Ricciuto, D. M.: Evaluating runoff simulations from the Community Land Model 4.0 using observations from flux towers and a mountainous watershed, J. Geophys. Res., 116, D24120, doi:10.1029/2011JD016276, 2011.

Loveland, T. R. and Belward, A. S.: The IGBP-DIS global $1 \mathrm{~km}$ land cover data set, DISCover: First results, Int. J. Remote Sens., 18, 3291-3295, 1997.

Maslowski, W., Cassano, J., Gutowski, W., and Lettenmaier, D.: Regional Arctic Climate System Model (RACM) - Development and Selected Results. Geophys. Res. Abstr., 13, EGU2011-9648,
EGU General Assembly 2011, Vienna, Austria, 2011.

MODIS Land Sience Collection 6: Test, NASA, available at: http://landweb.nascom.nasa.gov/cgi-bin/QA_WWW/newPage. cgi?fileName=sciTestMenu_C6 (last access: 19 September 2012), 2012.

Montesano, P. M., Nelson, R., Sun, G., Margolis, H., Kerber, A., and Ranson, K. J.: MODIS tree cover validation for the circumpolar taiga-tundra transition zone, Remote Sens. Environ., 113, 21302141, 2009.

Oleson, K. W., Lawrence, D. M., Bonan, G. B., Flanner, M. G., Kluzek, E., Lawrence, P. J., Levis, S., Swenson, S. C., Thornton, P. E., Dai, A., Decker, M., Dickinson, R., Feddema, J., Heald, C. L., Hoffman, F., Lamarque, J.-F., Mahowald, N., Niu, G.-Y., Qian, T., Randerson, J., Running, S., Sakaguchi, K., Slater, A., Stockli, R., Wang, A., Yang, Z.-L., Zeng, X., Zeng, X.: Technical Description of version 4.0 of the Community Land Model (CLM), NCAR/TN-478+STR, available at: www.cesm.ucar.edu/models/cesm1.0/clm/CLM4_Tech_Note. pdf (last access: 19 September 2012), 2010.

Pisek, J. and Chen, J. M.: Comparison and validation of MODIS and VEGETATION global LAI products over four BigFoot sites in North America. Remote Sens. Environ., 109, 81-94, 2007.

Poulter, B., Ciais, P., Hodson, E., Lischke, H., Maignan, F., Plummer, S., and Zimmermann, N. E.: Plant functional type mapping for earth system models, Geosci. Model Dev., 4, 993-1010, doi:10.5194/gmd-4-993-2011, 2011.

Ramankutty, N., Evan, A. T., Monfreda, C., and Foley, J. A.: Farming the planet: 1 . Geographic distribution of global agricultural lands in the year 2000, Global Biogeochem. Cy., 22, GB1003, doi:10.1029/2007GB002952, 2008.

Skamarock, W. C., Klemp, J. B., Dudhia, J., Gill, D. O., Barker, D. M., Duda, M. G., Huang, X. Y., Wang, W., and Powers, J. G.: A Description of the Advanced Research WRF Version 3, NCAR Technical Note, NCAR/TN-475+STR, 123 pp., 2008.

Still, C. J., Berry, J. A., Collatz, G. J., and DeFries, R. S.: Global distribution of $\mathrm{C} 3$ and $\mathrm{C} 4$ vegetation: Carbon cycle implications, Global Biogeochem. Cy., 17, 1006-1019, 2003.

Subin, Z. M., Riley, W. J., Jin, J., Christianson, D. S., Torn, M. S., and Kueppers, L. M.: Ecosystem Feedbacks to Climate Change in California: Development, Testing, and Analysis Using a Coupled Regional Atmosphere and Land Surface Model (WRF3CLM3.5), Earth Interact., 15, 1-38, 2011.

Weiss, M., Baret, F., Garrigues, S., and Lacaze, R.: LAI and fPAR CYCLOPES global products derived from VEGETATION, Part 2: Validation and comparison with MODIS collection 4 products, Remote Sens. Environ., 110, 317-331, 2007.

Willmott, C. J. and Matsuura, K.: Terrestrial air temperature and precipitation: Monthly and annual climatologies (Version 2.0.1), available at: http://climate.geog.udel.edu/ climate/html $\backslash$ pages/ download.html (last access: 12 September 2012), 2000.

White, M. A., Shaw, J. D., and Ramsey, R. D.: Accuracy assessment of the vegetation continuous field tree cover product using 3954 ground plots in the southwestern USA, Int. J. Remote Sens., 26, 2699-2704, 2005.

Yuan, H., Dai, Y., Xiao, Z., Ji, D., and Shangguan, W.: Reprocessing the MODIS Leaf Area Index products for land surface and climate modeling, Remote Sens. Environ., 115, 1171-1187, 2011. 